\title{
An analysis of surface breakup induced by laser-generated cavitation bubbles in a turbulent liquid jet
}

\author{
Jiayi Zhou ${ }^{1} \cdot$ Mats Andersson ${ }^{1}$ (D)
}

Received: 31 July 2020 / Revised: 13 October 2020 / Accepted: 15 October 2020

(c) The Author(s) 2020

\begin{abstract}
The breakup of turbulent liquid jets by cavitation bubbles was investigated by artificially introducing them by focusing laser light into the jet. The induced surface deformations and ejected liquid structures were characterized using shadowgraphy with a high-speed video camera. The flow velocity of the liquid jets, which were ejected from a $6 \mathrm{~mm}$ nozzle, was varied by adjusting the injection pressure from 1 to 5 bar. Deionized water and a dipropylene glycol-water mixture were used to compare the breakup of liquid jets with different surface tension and viscosity. Surface deformation and breakup were found to occur in two stages. One was early breakup of liquid strings into tiny droplets. This was followed by the formation of a larger structure separating into ligaments and larger drops. Averaged time-resolved one-dimensional plots were introduced and implemented to analyze breakup statistically, to address the problem of shot-to-shot variations in the breakup due to the turbulent condition of the jets. Bubble-induced breakup could easily be distinguished from spontaneous breakup with this method. Both the position of bubble formation and the injection pressure had an influence on the scale of the breakup. The deformation of the jet surface was highly affected by shear. The structure of the deformation became less intact when the surface tension was lower. The sizes of the drops produced during the second stage of breakup were analyzed. The bubbleinduced breakup produced smaller drops than the spontaneous breakup at lower injection pressure. As expected, lower surface tension favored droplet detachment and smaller sized drops.
\end{abstract}

Mats Andersson

f3cma@ chalmers.se

1 Department of Mechanics and Maritime Sciences, Chalmers

University of Technology, Gothenburg, Sweden 


\section{Graphic abstract}

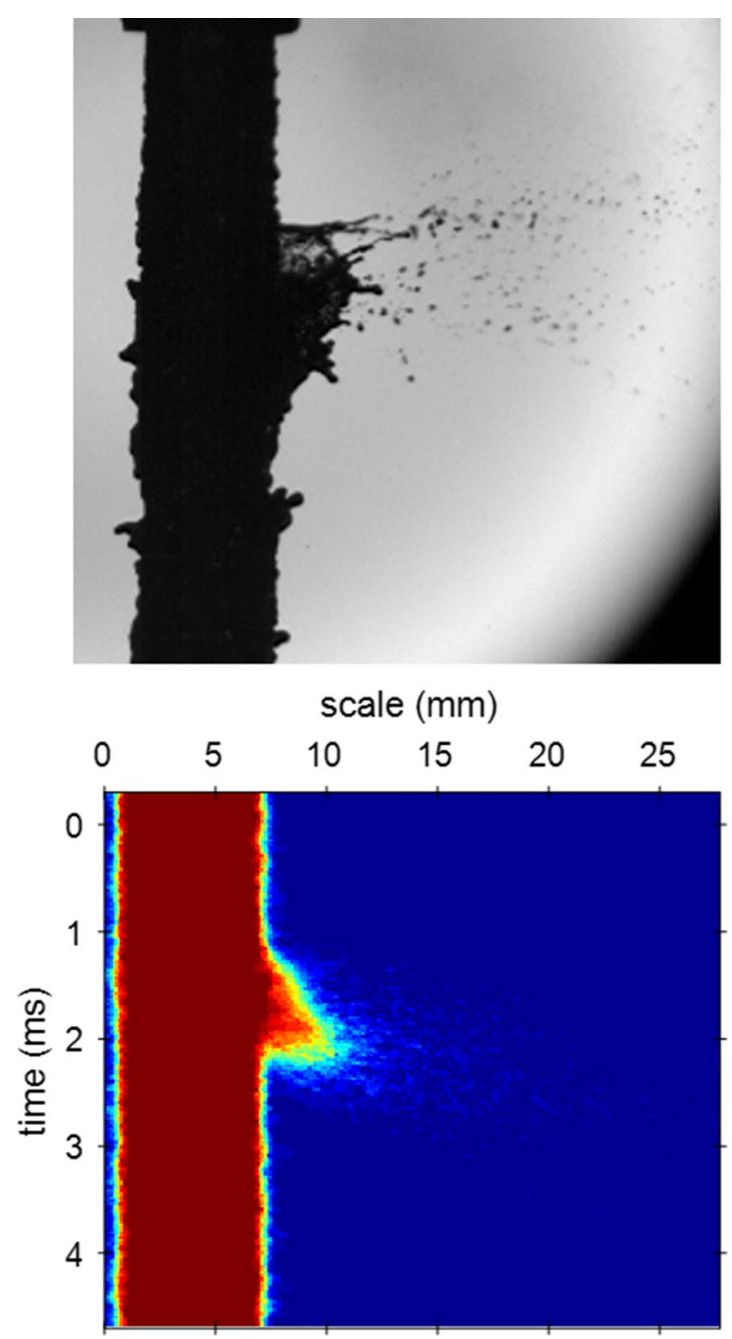

\section{Introduction}

The collapse of vapor cavities, often called cavitation bubbles, has drawn a lot of research attention especially for the collapse close to the liquid-gas interface (Ji et al. 2017; Koukouvinis et al. 2016; Kyriazis et al. 2019; Obreschkow et al. 2006). The collapse usually results in deformation of interface. This phenomenon has been investigated with various applications, such as underwater explosion (Keller and Kolodner 1956; Petrov and Schmidt 2015), the laserinduced forward transfer technique (LIFT) (Adrian et al. 1987; Duocastella et al. 2010), jet primary break-up (Örley et al. 2015), needle-free injection systems (NFIS) (Kyriazis et al. 2019; Tagawa et al. 2012) and so on. The interface can attain a variety of shapes depending on the specific application. Fundamental studies often focus on the bubble collapse

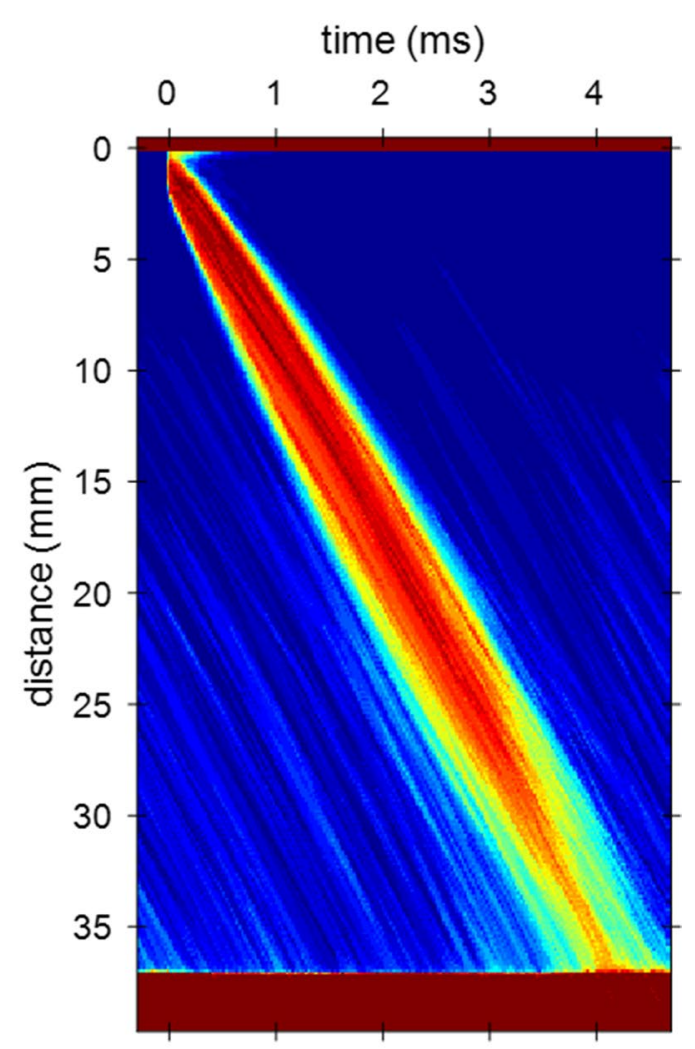

event close to a flat free surface (Bempedelis et al. 2020; Blake and Gibson 1981; Chahine 1977; Kang and Cho 2019; Patrascioiu et al. 2014a, b; Robinson et al. 2001; Supponen et al. 2015; Zhang et al. 2016). Remarkable experimentation on cavitation bubble collapse within a liquid droplet was done in microgravity (Obreschkow et al. 2006). Fine details of the laser disruption of a hemispheric drop and the formation of microjets from microbubbles sitting under the free surface were revealed by high-speed imaging (Thoroddsen et al. 2009).Triggered by different motivations, such as targets for high-power applications (Kirk et al. 2001) and laser ablation (Dell'Aglio et al. 2017), studies were also done on the interaction between a collapsing bubble and a cylindrically curved free surface. The growth and collapse of lasergenerated cavitation bubbles inside free-falling liquid water jets were studied by Robert et al. (2007). Bubble behavior in 
different experimental configurations, i.e. bubble to jet diameter ratio and eccentricity coefficient, were presented. The maximum ejecting speeds of microjets and droplets were recorded and found to be affected by both the bubble-to-jet diameter ratio and the eccentricity coefficient.

Unlike the studies of bubble collapse-induced deformation of regular-shaped surfaces, where the bubble within the liquid phase can be precisely generated and clearly observed, and the deformation of the surface is highly reproducible, studies of bubble collapse-induced breakup for turbulent jets faces the uncertainties in bubble characterization and shotto-shot variation of breakup on the turbulent surface of jet. Similar conditions can be found in effervescent atomization where liquid together with gas is ejected from the nozzle to enhance atomization (Gadgil and Raghunandan 2011; Sovani et al. 2001). Once the gas bubble leaves the nozzle, it expands rapidly due to a sudden pressure drop, thereby shattering the liquid into ligaments and drops. The breakup of the liquid jet in effervescent atomization usually has a radial distribution along the jet axis, while for cavitation bubble-induced breakup, the breakup basically goes along the cross-flow direction (Robert et al. 2007). Another relevant condition comes from a recent study of the breakup of a flash-boiling jet in a low pressure environment (Alghamdi et al. 2019). By systematically controlling the ambient pressure, nucleation and expansion of single bubbles and bubble burst-induced breakup of the jet were observed with an ultra-high speed imaging setup. The atomized drops were found to be ejected in all directions around the jet, which makes it distinct from the jet breakup in the study of Robert et al. (2007). For high pressure fuel injection systems, cavitation which originates inside the nozzle of a liquid atomizer (Nurick 1976) is believed to be an important mechanism causing atomization in the sprays (Soteriou et al. 1995). It contributes to jet breakup mainly in two ways. One is that the collapse of cavitation bubbles increases the turbulence of the in-nozzle flow (He and Ruiz 1995) and liquid core in the primary breakup region (Baumgarten et al. 2002). The other is that the bubble collapse events close to the liquid-gas interface in the primary breakup region generate a jet growing toward the gas phase side of the interface (Örley et al. 2015).

A turbulent jet usually has relatively high flow velocity, i.e. higher Reynolds number and Weber number, compared to a laminar liquid jet. For different Reynolds number and Weber number ranges, the dominant breakup mechanisms are different. The well-known four regimes of jet breakup, i.e. Rayleigh breakup, first wind-induced regime, second wind-induced regime and atomization regime, were proposed by Reitz (1978) and Lin and Reitz (1998). More mechanisms beside bubble collapse, for example, Rayleigh instability, turbulence, aerodynamic shear, etc., may contribute to the jet breakup (Kumar and Sahu 2020; Lin and Reitz
1998; Mittal et al. 2020; Reitz 1978; Sallam et al. 2002; Singh et al. 2020; Tadjfar and Jaberi 2019; Wang and Fang 2015). One needs to distinguish the breakup induced by bubble collapse from other mechanisms. A previous study of laser-generated bubble-induced breakup of turbulent liquid water jets revealed that the distance of the laser focus to the center axis of the nozzle, i.e. the eccentricity, was a main factor that affected breakup (Zhou and Andersson 2018). A normalized spray area change rate was introduced to investigate different breakup types, but, it did not provide information on the breakup structure. In this study, a time-resolved one-dimensional analysis is proposed and implemented to analyze the images of sprays. It provides more detailed information on the breakup of the spray and could serve as a tool for quantitative comparison with results of numerical simulations. A dipropylene glycol and water mixture was used to investigate the influence of surface tension to breakup. Drop size information for the different cases is presented and analyzed.

\section{Methodology}

\subsection{Experiment setup}

In this study, jet breakup induced by laser-generated cavitation bubbles was investigated at turbulent flow conditions. Laser light was focused into the liquid jet right outside the nozzle, and video sequences of the liquid ejection and breakup events were recorded. The experimental setup is schematically illustrated in Fig. 1. The setup is composed of three main parts. The first part included all the equipment for the liquid jet. The jet was ejected from an acrylic nozzle whose internal diameter was $6 \mathrm{~mm}$ as illustrated in Fig. 1b. The length of the straight section of the nozzle was $150 \mathrm{~mm}$. The inlet of the nozzle was rounded to make sure no cavitation formed due to the sudden change of flow direction. Right upstream of the nozzle there was a turbulence generation tip, which had a four-hole honeycomb design, to ensure a fully developed turbulent flow at the exit of the nozzle. More detailed information on the nozzle and its internal flow is available in Sedarsky et al. (2015). The nozzle was connected to a cylindrical container which contained enough liquid for steady ejection over several seconds after startup. The container was connected to a pressurized nitrogen botthe via a regulator. In order to vary the flow velocity, the injection pressure was tuned to cover a range of $1-5$ bar by the regulator.

The second part performed the function of providing and focusing the laser light to generate bubbles. Laser light pulses were generated by a Nd: YAG laser (Spectra-Physics LAB170) and the second harmonic output at a wavelength of $532 \mathrm{~nm}$, pulse duration of $8 \mathrm{~ns}$ and beam diameter of 


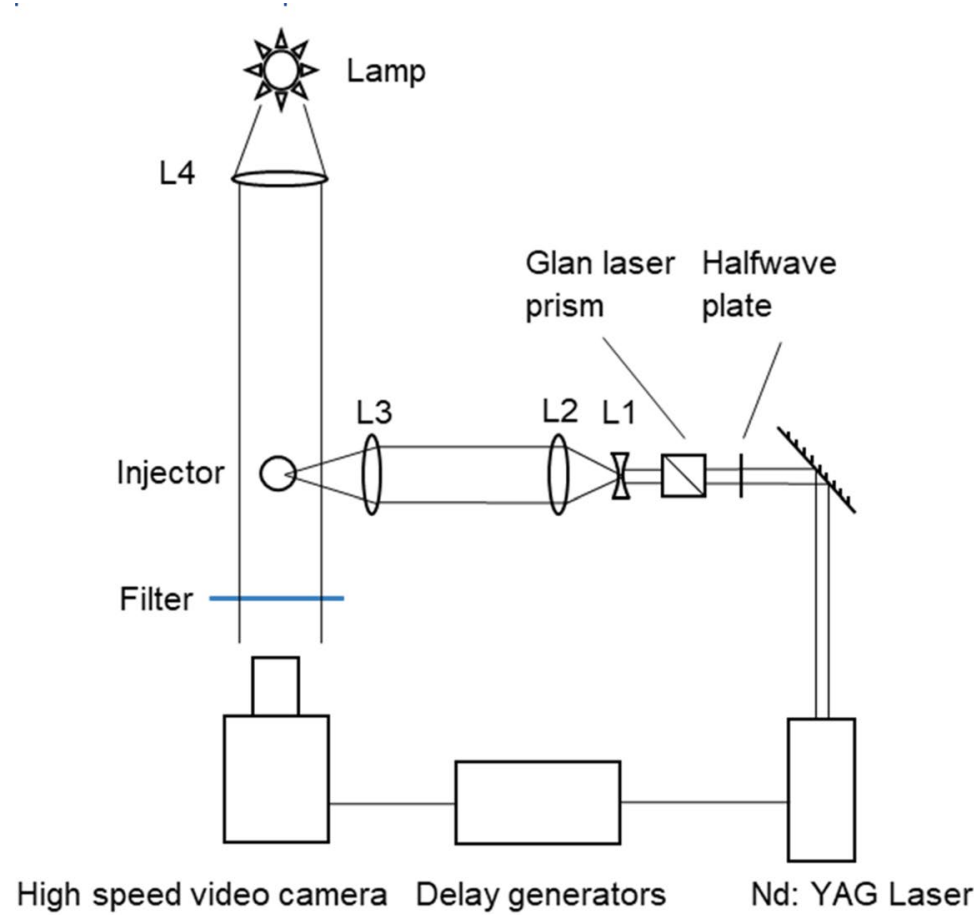

(a)

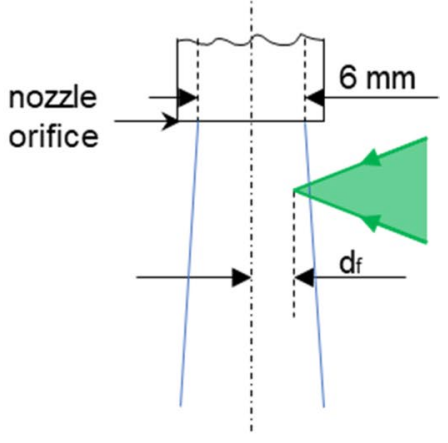

(b)

Fig. 1 Schematic of the experiment setup. a Overhead view of the optical setup. b Side view of the nozzle orifice and indication of the laser focus position

$9 \mathrm{~mm}$ was used. The light was attenuated by the combination of a half-wave plate and a Glan laser prism, with which the energy of the laser pulses was tuned by rotating the half-wave plate which was installed on a rotating mount. The attenuated laser light was expanded with a concave lens $\mathrm{L} 1(f=-20 \mathrm{~mm})$ and collimated by a positive lens L2 $(f=+100 \mathrm{~mm})$. The expanded light was focused around $1 \mathrm{~mm}$ below the injector nozzle by lens L $3(f=+150 \mathrm{~mm})$ which was mounted on a translation stage. L1, L2 and L3 were all achromatic doublets which could minimize spherical aberrations. The position of the laser focus was adjustable by moving L3 along the laser beam direction. As shown in Fig. $1 \mathrm{~b}$, the position of the laser focus is denoted by ' $d_{\mathrm{f}}$ ' which is the distance of the focus to the central axis of the nozzle. The pulse energy was tuned to be $5 \mathrm{~mJ}$ which was measured after L3.

The third part performed shadowgraphy on the liquid jet. This part consisted of a plasma lamp (THORLABS HPLS200) as a white light source, a lens L4 to collimate the light, a high-speed video camera (Phantom v1210 with Nikkor $24-85 \mathrm{~mm}$ zoom lens and $2 \times$ teleplus pro 300 ) to record shadowgram videos of the liquid jet, and a band-pass filter to protect the camera from scattered laser light. The recording resolution of the camera was set to $640 \times 400$ pixels which gave the videos a pixel resolution of 8.4 pixels per millimeter. Three delay generators (SRS DG535) were used for generating the signals for the pulsed laser, which was running at $10 \mathrm{~Hz}$, the video camera, which was taking videos at $41 \mathrm{k}$ frames per second and exposure time of $0.5 \mu \mathrm{s}$, and synchronizing the laser and the camera.

The working liquids used in this study included deionized water and a blend of $10 \%$ dipropylene glycol (volume percentage) and deionized water. In the following text, the blend is called DPG10 for ease of presentation. Surface tension of the liquids was measured by Bubble Pressure Tensiometer (KRUSS BP50) at $25^{\circ} \mathrm{C}$. The density and viscosity of water were obtained from the data by Kestin et al. (1978). The density and viscosity of DPG10 were estimated by using the empirical equation in the study of Sun and Teja (2004). Properties of the liquids are summarized in Table 1 . The mass flow rate of the water jets was estimated by measuring the mass of ejected liquid for a certain time. The velocity of the flow at the nozzle exit was then calculated based on the

Table 1 Properties of the liquids

\begin{tabular}{lcll}
\hline Density $\left(\mathrm{kg} / \mathrm{m}^{3}\right)$ & $\begin{array}{l}\text { Surface tension } \\
(\mathrm{mN} / \mathrm{m})\end{array}$ & $\begin{array}{l}\text { Dynamic } \\
\text { viscosity } \\
(\mathrm{mPa} \mathrm{s})\end{array}$ \\
\hline Water & 997 & 72.4 & 0.89 \\
DPG10 & 1010 & 54.6 & 2.3 \\
\hline
\end{tabular}


mass flow rate, the density of the liquid and the diameter of the orifice. Hence, Reynolds numbers and Weber numbers of the flow at the exit of the nozzle were calculated based on the equations

$\operatorname{Re}=\frac{\rho U D}{\mu}, \mathrm{We}=\frac{\rho U^{2} D}{\sigma}$,

where $\rho$ is the density of the liquid, $U$ the flow velocity at the nozzle exit, $D$ the internal diameter of the nozzle, $\mu$ the dynamic viscosity of the liquid, and $\sigma$ the surface tension of the liquid. The values are shown in Table 2.

\subsection{A statistical method to describe breakup}

A difficulty in analyzing bubble-induced breakup of a turbulent jet was that the breakup structure could be quite different from shot to shot. There were two main imperfections contributing to this difficulty. One was the wrinkled surface of the jet, which distorted the incoming laser beam. The distortion might result in a transient larger or smaller focusing angle. The focusing angle could affect the shape of the laser-induced plasma (Tian et al. 2016; Vogel et al. 1996), and the shape and dynamics of the cavitation bubble (Sinibaldi et al. 2019). The wrinkled surface also affected the interaction between the bubble and the surface, as it is known that shape of the surface affects the bubble and breakup dynamics (Obreschkow et al. 2006). The other factor was the turbulent flow, which might affect the growth of the cavity induced by the focused laser pulse. Although the use of a doublet lens already reduced pulse-to-pulse plasma fluctuations (Tian et al. 2019), some shape and size variation of the bubbles were still inevitable for the reasons stated above. Based on knowledge of bubble-induced breakup of flat free surfaces and laminar liquid jets, the size of the bubble and the distance between the bubble and the surface affect the characteristics of the breakup, such as structure and jetting speed (Blake and Gibson 1981; Chahine 1977; Kang and Cho 2019; Patrascioiu et al. 2014a, b; Robert et al. 2007; Robinson et al. 2001; Supponen et al. 2015; Zhang et al. 2016). Therefore, shot-to-shot variations of the lasergenerated cavitation bubbles in turbulent jets for this study was expected to result in variation of the bubble-induced breakup of the jet. Owing to this uncertainty, it was necessary to analyze multiple images statistically. Even if there are uncertainties in the character of the laser focus contributing to statistical fluctuations, relevant studies of parameter variation could still be performed as demonstrated by the high sensitivity to moving the laser focus position by half$\mathrm{mm}$ steps along the jet radius as described in the Results section. In a previous study (Zhou and Andersson 2018), by analyzing the averaged spray area from the binarized images, the position of the laser focus was found to be the main factor that affected breakup. However, that study did not provide information on the breakup structure. A common way to present averaged images is to make averages of single shot images at a single time step of individual conditions (Mitroglou et al. 2014; Purwar et al. 2015; Westlye et al. 2016). However, to investigate the time evolution one then needs to examine and compare series of averaged images for different operation conditions. If instead, producing images with time on one axis and one spatial coordinate on the other, a comparison of the time evolution between different cases using just single images is facilitated. So, depending on the purposes one can choose two of the three: time, vertical or horizontal coordinate with a fixed value of the third. In this study, this new statistical method is proposed and applied to visualize evolution of the breakup in one plot. The use of these time-resolved one-dimensional plots is also useful for comparison between the bubble-induced and the spontaneous breakup.

A one-dimensional (1D) analysis of the images was implemented to analyze and compare bubble-induced breakup under different experimental conditions. This method starts with binarization of the video frames to distinguish liquid and gas phases. The binarization was performed with the method proposed by Otsu (1979). Then the values along a line in the binarized video frame located at a specific position on the frame are determined. As shown in Fig. 2, diagram (b) presents pixel values in the binarized image (a) along the red line which is along the flow direction and located at a distance of $d_{\mathrm{c}}$ from the central axis of the nozzle. Diagram (c) presents pixel values in image (a) along the green line which is in the cross-flow direction and located at a distance of $d_{\mathrm{o}}$ from the orifice of nozzle. By putting the readings along one dimension at the same position from each frame of a video side by side, time-resolved 1D plots can be obtained as shown in Fig. 3. Plot (a) presents the time-resolved $1 \mathrm{D}$ reading along the red line shown in Fig. 2a. Readings from each frame are sorted from left to
Table 2 Flow conditions at the exit of nozzle in the form of Reynolds number and Weber number with respect to injection pressure

\begin{tabular}{llllllllll}
\hline Injection pressure (bar) & 1 & 1.5 & 2 & 2.5 & 3 & 3.5 & 4 & 4.5 & 5 \\
\hline Re for water/10 & 1.27 & 1.59 & 2.01 & 2.40 & 2.87 & 3.13 & 3.87 & 4.48 & 5.01 \\
Re for DPG10/10 & 0.493 & 0.616 & 0.779 & 0.930 & 1.11 & 1.21 & 1.50 & 1.73 & 1.94 \\
We for water/10 $^{5}$ & 0.296 & 0.464 & 0.741 & 1.06 & 1.51 & 1.79 & 2.74 & 3.67 & 4.59 \\
We for DPG10/10 & 0.388 & 0.607 & 0.969 & 1.38 & 1.97 & 2.34 & 3.59 & 4.81 & 6.00 \\
\hline
\end{tabular}



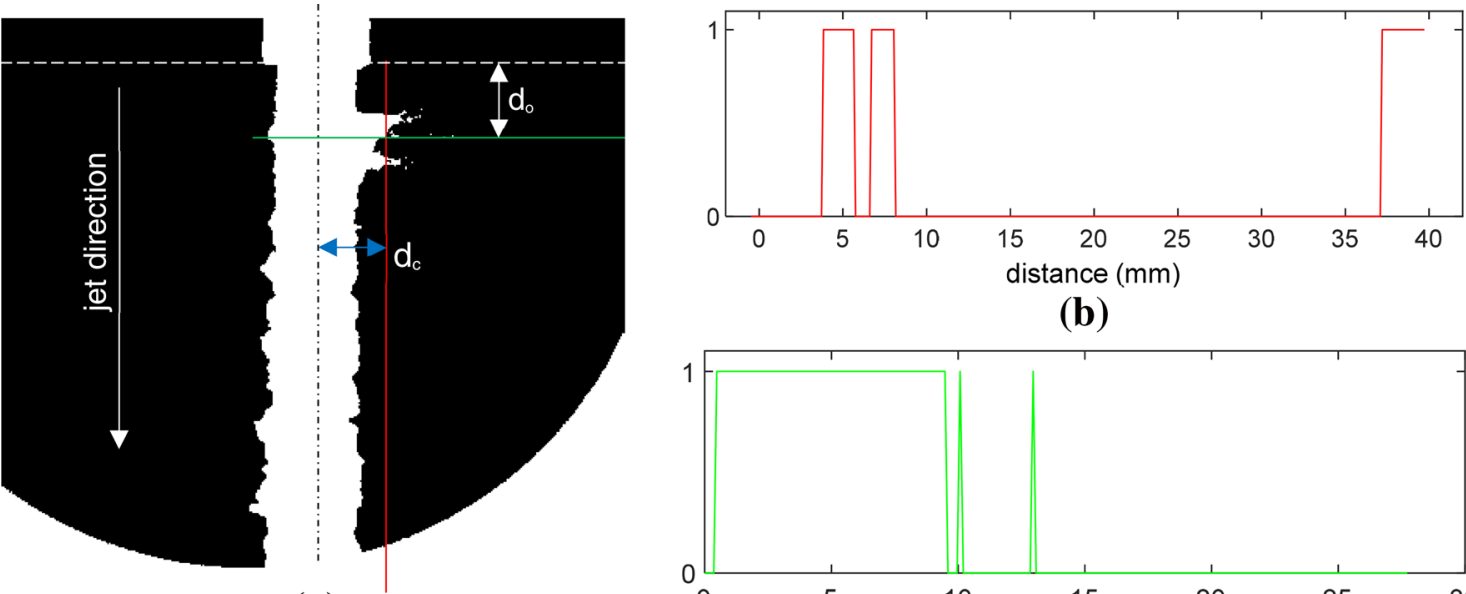

(b)

(a)

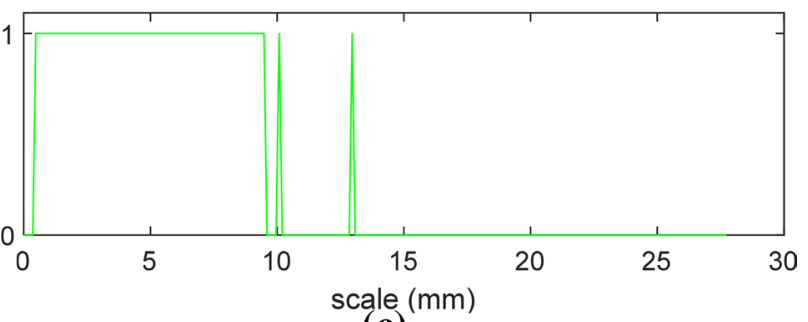

(c)

Fig. 2 1D readings of a binarized video frame

Fig. 3 Time-resolved 1D plots a along the flow direction at a distance of $d_{c}$ from the nozzle axis and $\mathbf{b}$ along the cross-flow direction at a distance of $d_{\mathrm{o}}$ from the orifice, respectively, of a binarized video segment

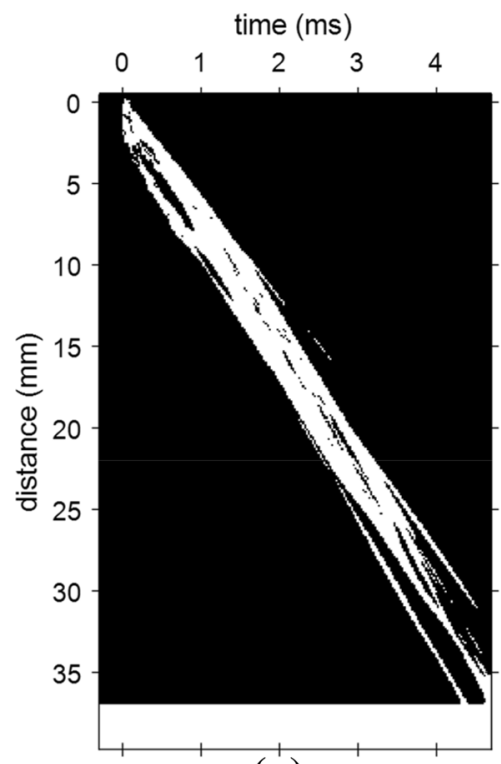

(a)

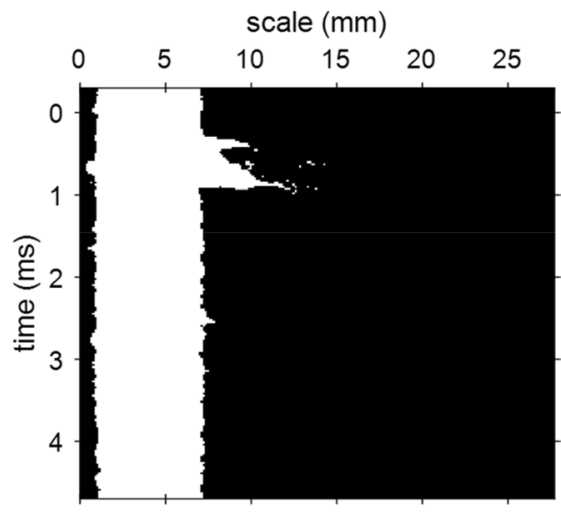

(b) right with increasing time. Time zero indicates the moment of laser pulse. The $Y$-axis indicates the distance to the nozzle orifice. Plot (b) presents the time-resolved 1D reading along the green line shown in Fig. 2a. Readings from each frame are sorted from top to bottom with increasing time. The X-axis indicates the horizontal length scale of the plot. Averaged time-resolved 1D plots, which will be presented and discussed in Sect. 3.2, are obtained from video segments of repeated experiments. The averaged plot shows the timeresolved probability distribution of the breakup resulting in the presence of liquid ligaments, fragments and droplets in one dimension at a certain position and direction of the binarized videos. Owing to repeatable steady injection of the jet over repeated experiments, the breakup events always passed certain position at certain time, so the plot can show the averaged structure and evolution of the breakups properly.

\section{Results and discussions}

To characterize the time evolution and mechanism of the breakup at various conditions, individual video sequences of typical breakup sequences at various operation conditions are analyzed. For a comparison between conditions, averaged data are used, both based on time-resolved one-dimensional 
plots showing probability to detect ejected liquid at various positions and times, and drop size distributions.

\subsection{The character of the bubble-induced breakup of the jet}

The image series shown in the following figures were extracted from individual sequences recorded by the highspeed video camera. Experimental conditions including injection pressure and position of the laser focus are presented in the captions. The number below each image indicates the time delay from the moment of the laser triggering. The nozzle exit can be seen at the top of each image and the flow direction is from top to bottom. The laser light was introduced from the right side of the jet in the images. The left side of the jet was also included in the images as a reference.

Figure 4 shows the case when the injection pressure was 1 bar and the laser was focused at a relatively deep position in the jet, i.e. $2 \mathrm{~mm}$ from the nozzle axis. Based on the observation from the left side of the jet, there were surface waves but no spontaneous breakup of ligament or droplet from the jet in the field of view. On the right side of the jet, obvious disturbances induced by laser-generated bubble were distorting the jet surface. From 0.025 to $0.05 \mathrm{~ms}$, the surface burst to form an irregular deformation. Streaks of finely dispersed drops (giving a foggy impression) appear on the tip of the deformation at $0.05 \mathrm{~ms}$. In the following images, the streaks were followed by more distinct stings which were growing and breaking up into tiny droplets from 0.1 to $0.5 \mathrm{~ms}$. The strings were followed by a larger deformed structure which grew relatively slowly. Almost all the strings had broken into droplets by $1 \mathrm{~ms}$. The larger structure which arrives later was stretching into ligaments as shown in the images from 1 to $3 \mathrm{~ms}$. The ligaments did not grow significantly in the cross-flow direction of the jet. The left ends of the ligaments were still connected to the jet and moving along with the jet in the flow direction, while the right sides of the ligaments were slowed by air resistance. This resulted in tilted ligaments and was believed to facilitate the ligament breakup process (Reitz 1986). Most of the ligaments had broken into droplets by $3 \mathrm{~ms}$. The drops produced by the late ligaments were clearly much larger than those from the earlier $(\leq 1 \mathrm{~ms})$ strings.

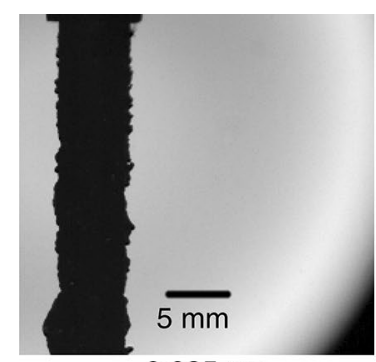

$0.025 \mathrm{~ms}$

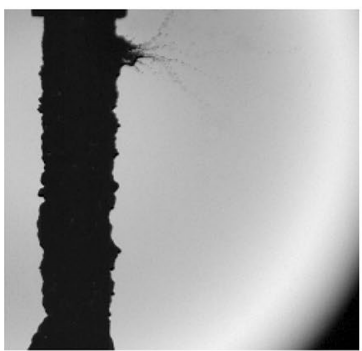

$0.3 \mathrm{~ms}$

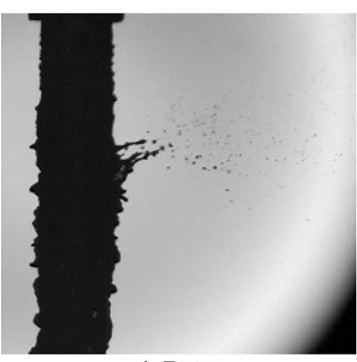

$1.5 \mathrm{~ms}$

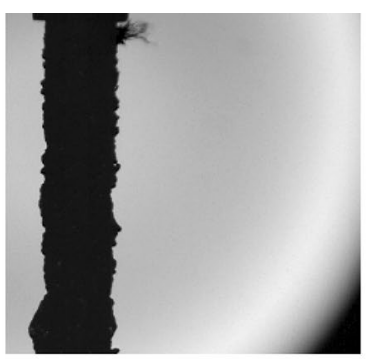

$0.05 \mathrm{~ms}$

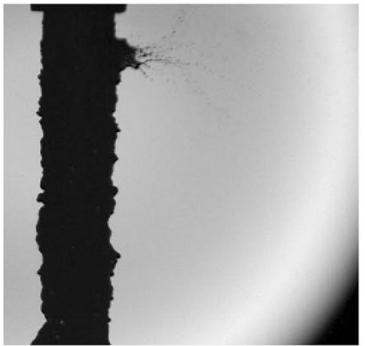

$0.4 \mathrm{~ms}$

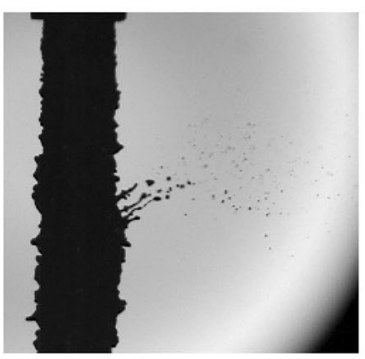

$2 \mathrm{~ms}$

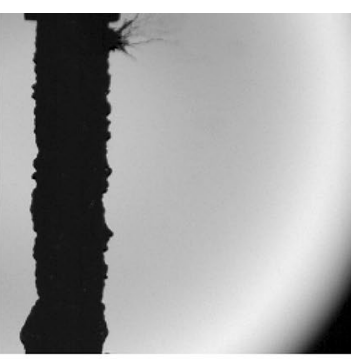

$0.1 \mathrm{~ms}$

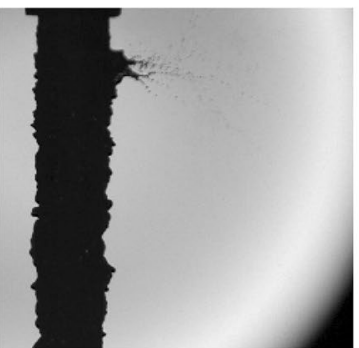

$0.5 \mathrm{~ms}$

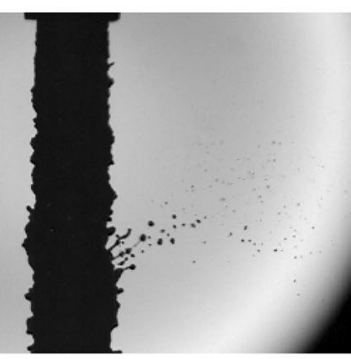

$2.5 \mathrm{~ms}$

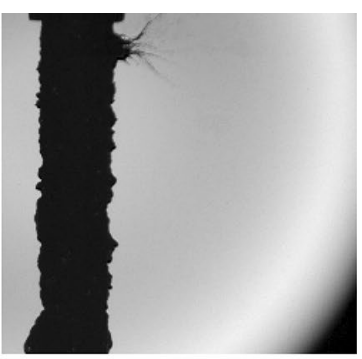

$0.2 \mathrm{~ms}$

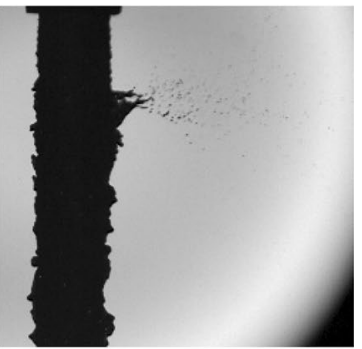

$1 \mathrm{~ms}$

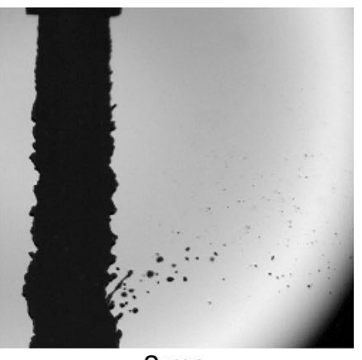

$3 \mathrm{~ms}$

Fig. 4 Images of bubble-induced breakup of water jet when the injection pressure was 1 bar and $d_{\mathrm{f}}=2 \mathrm{~mm}$ 
When the laser light was focused $2.5 \mathrm{~mm}$ from the nozzle axis (closer to the jet surface), surface breakup was more massive in general as shown in Fig. 5. Similar to the previous case, liquid strings were growing and breaking into tiny droplets at the early stage (from 0.025 to $0.5 \mathrm{~ms}$ ). From $0.05 \mathrm{~ms}$, the deformation was evolving towards several directions. This phenomenon shows similarities with the cavitation bubble induced breakup of laminar water jets where the breakups appeared like a fork and evolved towards three directions (Robert et al. 2007) and the multiple jets induced by the interaction between the bubble and the waviness of the free surface (Thoroddsen et al. 2009). The rapid expansion of a bubble close to a free surface can induce jetting outwards especially at the concave region on the surface. In the current study, the turbulent surface of the jet promoted ejections in multiple directions. Following the early stringlike breakup, a larger structure formed already at $0.2-0.3 \mathrm{~ms}$ and its height at the jet surface grew with time up to about $1.0 \mathrm{~ms}$. Its shape was affected by the aerodynamic shear, and as a result, the deformation of the jet surface attained roughly in the shape of a triangle which was denoted by a dashed triangle in the image of $1.5 \mathrm{~ms}$.
Bubble-induced jet breakup at higher injection pressures (higher jet velocity) is presented in Figs. 6 and 7. The scales of the breakup were smaller than those at 1 bar. Two main effects might contribute to this. One was that the more distributed deposited energy, due to rougher surface of the jet, made the laser focus less sharp. The other was that the increased turbulence of the flow within the jet could affect the growth, collapse and rebound of the cavitation bubble induced by the laser pulse. Both effects could result in smaller sized cavitation bubbles, and less energy directed towards ejection of liquid fragments and drops. As well established for the bubble collapse induced breakup of flat surfaces and laminar round jets, smaller bubble collapses lead to less pronounced surface deformations (Robert et al. 2007; Zhang et al. 2016). Regardless of the smaller scale of breakup at higher flow velocities, the morphological characteristics of these breakups were quite similar to those at 1 bar. At the early breakup stage as shown in the images of $0.1 \mathrm{~ms}$ and $0.5 \mathrm{~ms}$ in Figs. 6 and 7, liquid strings were growing and breaking into tiny droplets. At $1 \mathrm{~ms}$, the larger deformed structures following the strings were stretching and breaking into ligaments under the influence of inertia,

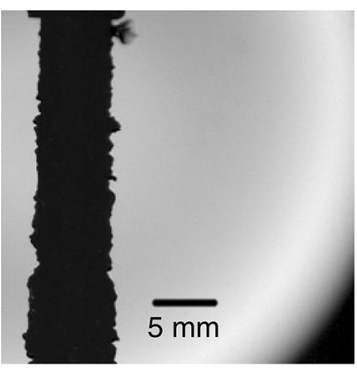

$0.025 \mathrm{~ms}$

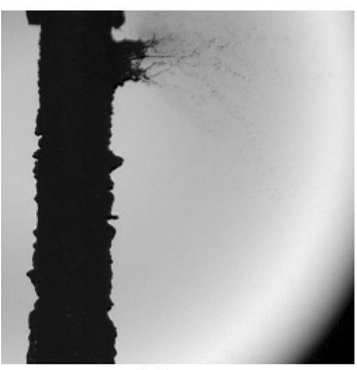

$0.3 \mathrm{~ms}$

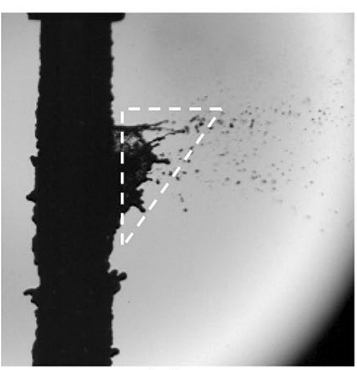

$1.5 \mathrm{~ms}$

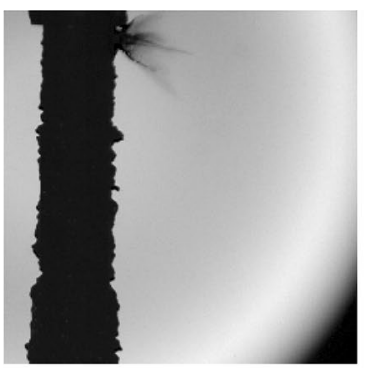

$0.05 \mathrm{~ms}$

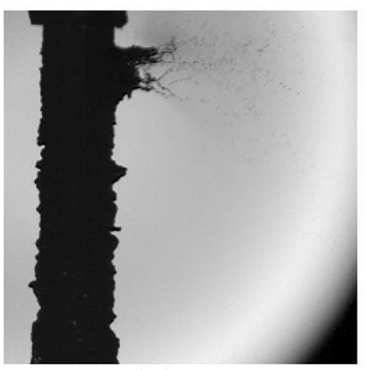

$0.4 \mathrm{~ms}$

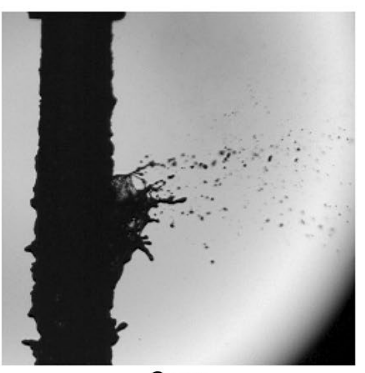

$2 \mathrm{~ms}$

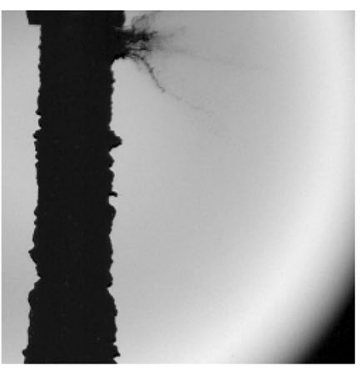

$0.1 \mathrm{~ms}$

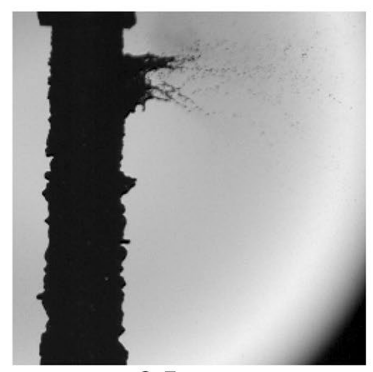

$0.5 \mathrm{~ms}$

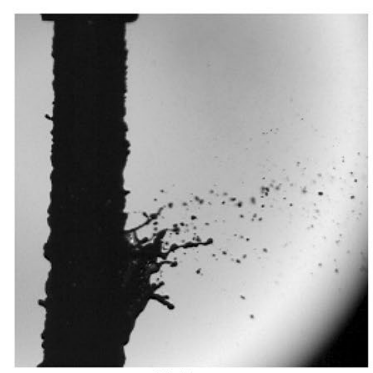

$2.5 \mathrm{~ms}$

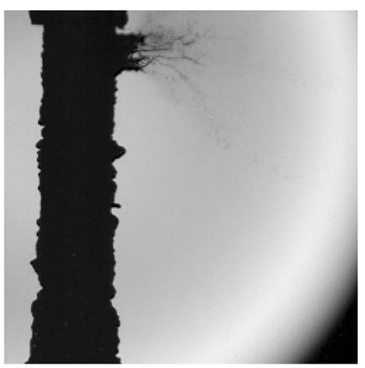

$0.2 \mathrm{~ms}$

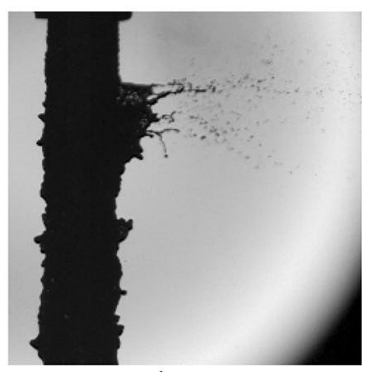

$1 \mathrm{~ms}$

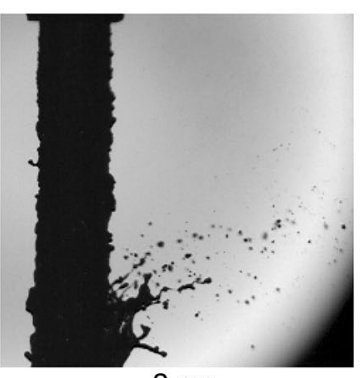

$3 \mathrm{~ms}$

Fig. 5 Images of bubble-induced breakup of water jet when the injection pressure was 1 bar and $d_{\mathrm{f}}=2.5 \mathrm{~mm}$ 


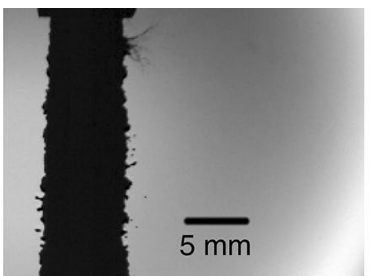

$0.1 \mathrm{~ms}$

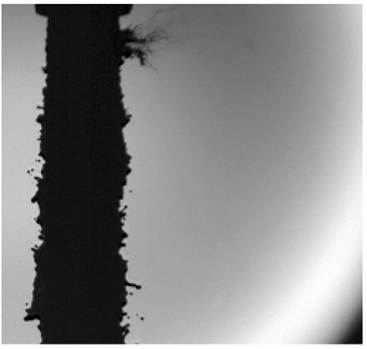

$0.1 \mathrm{~ms}$

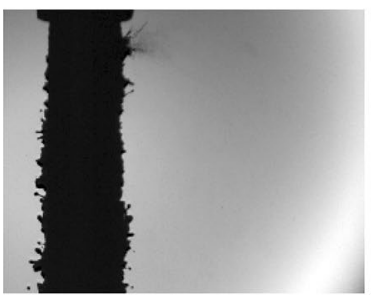

$0.1 \mathrm{~ms}$

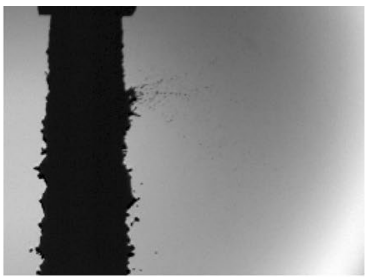

$0.5 \mathrm{~ms}$

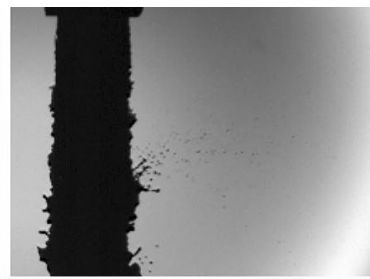

$1 \mathrm{~ms}$

(a) 3 bar, $d_{1}=2 \mathrm{~mm}$

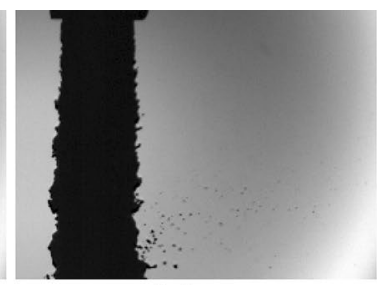

$1.5 \mathrm{~ms}$

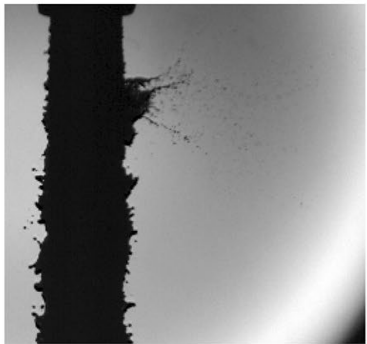

$0.5 \mathrm{~ms}$

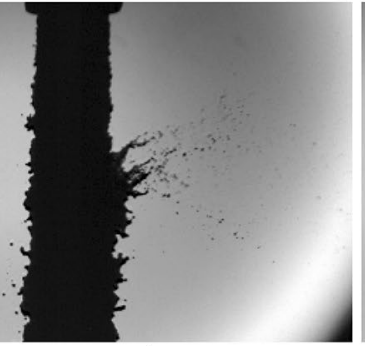

$1 \mathrm{~ms}$

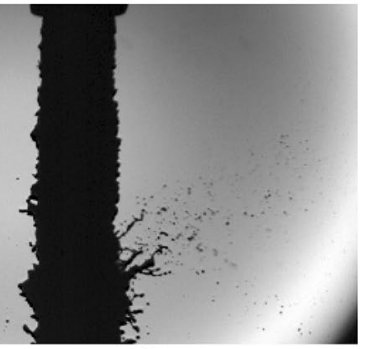

(b) 3 bar, $d_{f}=2.5 \mathrm{~mm}$

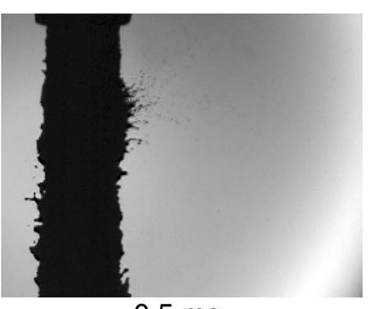

$0.5 \mathrm{~ms}$

(c) 3 bar, $d_{f}=3 \mathrm{~mm}$

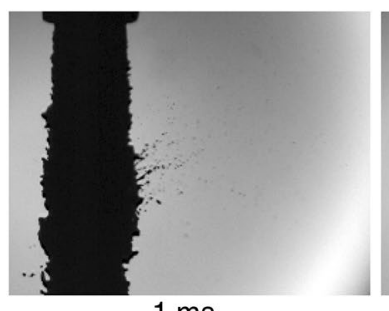

$1 \mathrm{~ms}$
$1.5 \mathrm{~ms}$

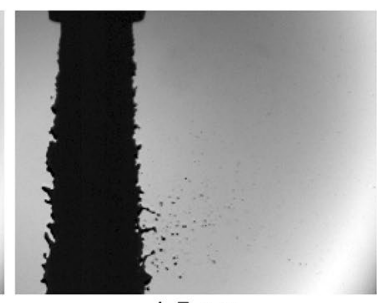

$1.5 \mathrm{~ms}$

Fig. 6 Images of bubble-induced breakup of water jet when the injection pressure was 3 bar

surface tension, and shear. Larger droplets compared to the tiny ones at early stage were detaching from the ligaments at $1.5 \mathrm{~ms}$. An important difference for cases of higher injection pressure compared to those of lower pressure was that the jet itself started to break up spontaneously as well. This could be observed on the left side of the jets in Figs. 6 and 7. As the injection pressure increased, the shorter (compared to the waves at lower injection pressure) wavelength surface waves resulted in more droplet detachments. These drops were larger than the tiny drops from the liquid strings, but comparable to the drops detached from the ligaments on the right side of the jets. A more detailed analysis of drop sizes will be presented below.

The overall characteristics of breakup with DPG10 liquid were very similar to the corresponding cases with water, and images are not presented here. However, due to the lower surface tension of DPG10, the jet already started to break up spontaneously at the injection pressure of 1 bar. Further comparisons between cases of water and DPG10 will be presented in the following sections.

As discussed above, the bubble-induced breakup of turbulent jets can be considered a two-stage process. During the early stage, thin liquid strings were stretching and breaking into tiny droplets. The later stage included the formation of larger deformed structure and ligaments, and breakup of the ligaments. In a previous study, where single laser-generated cavitation bubble was introduced close to flat free surfaces (Bempedelis et al. 2020), the surface area generation of the bubble-induced breakup was divided into three phases which corresponded to the bubble cycles. The first phase, during which a spike-like jet formed above the free surface, can be correlated to the early stage of the breakup in this study. The second stage, which included the formation of a crown-shaped jet and faster surface area generation, shares similar characteristics to the later stage in this study. The transition time from the first to the second phase in the previous study was around $0.2 \mathrm{~ms}$ which was comparable to the onset time of the larger breakup structure in this study of around $0.1-0.2 \mathrm{~ms}$ for the case shown in Fig. 4. In the study of bubble-induced breakup of laminar jets by Robert et al. (2007), the case of large eccentricity of bubble creation site $(\varepsilon=0.88)$, i.e. the bubble was created very close to the jet surface, is comparable to this study. In that case, there was a thin and diffuse jet formed at early time during the expansion 


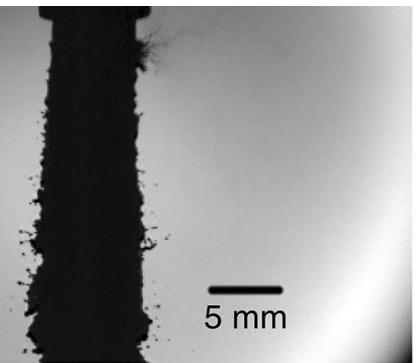

$0.1 \mathrm{~ms}$

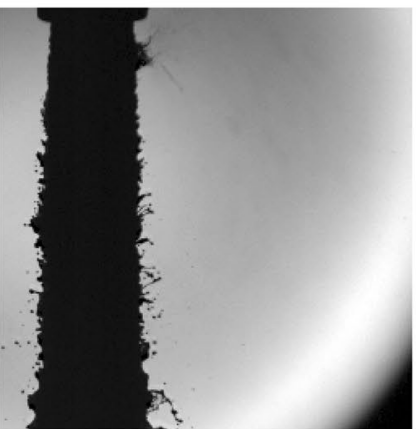

$0.1 \mathrm{~ms}$

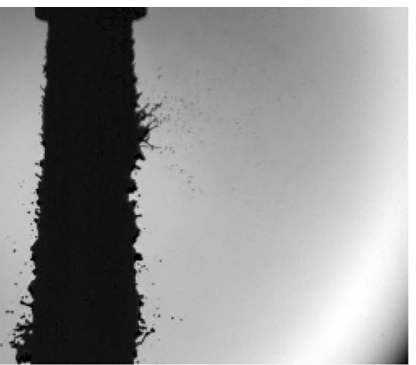

$0.5 \mathrm{~ms}$

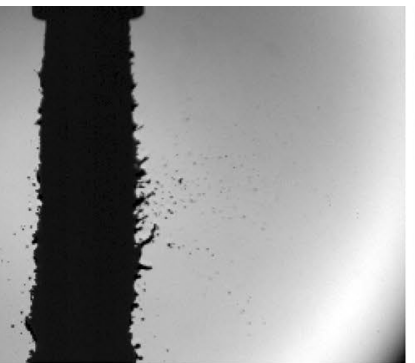

$1 \mathrm{~ms}$

(a) 5 bar, $d_{f}=2.5 \mathrm{~mm}$

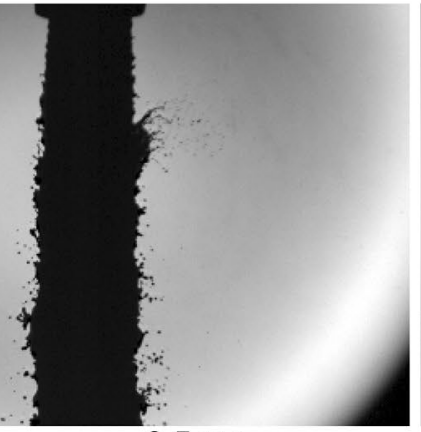

$0.5 \mathrm{~ms}$

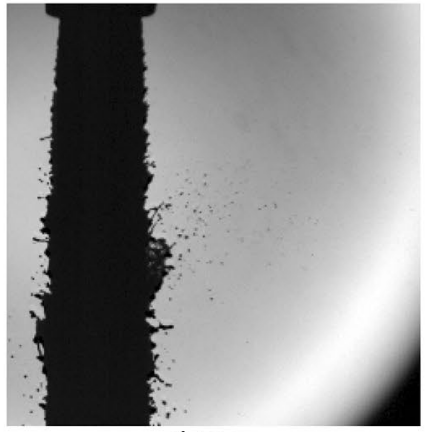

$1 \mathrm{~ms}$

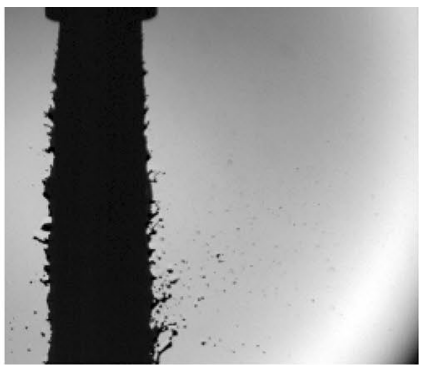

$1.5 \mathrm{~ms}$

(b) 5 bar, $d_{f}=3 \mathrm{~mm}$

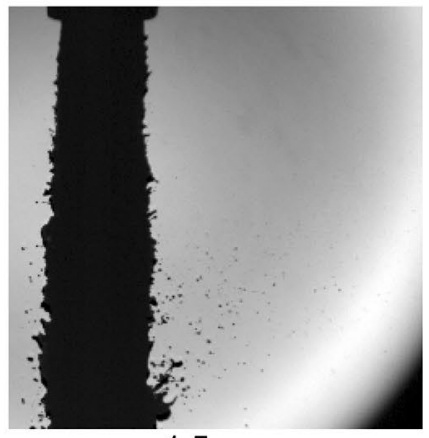

$1.5 \mathrm{~ms}$

Fig. 7 Images of bubble-induced breakup of water jet when the injection pressure was 5 bar

of the bubble and then a thicker jet followed the thin jet during the later bubble oscillation. Although the boundary conditions are less well-defined in this study, with turbulent flow conditions and a rough jet surface, the observed behavior can still be interpreted in the terms of a dynamic bubble interacting with a free surface.

\subsection{Averaged time-resolved one-dimensional plot}

In this section the location and amount of liquid ejected by breakup will be analyzed and compared for the different fluids and operation conditions. For this purpose, the timeresolved 1D plots were used. For a certain flow and bubble condition, the time-resolved breakup evolution was studied by locating the image reading line at various positions in the flow direction and cross-flow direction, as shown in Figs. 8, 9, 10, 11. The probability distribution is illustrated by the color map beside the plot. Unless otherwise indicated, the color maps of the plots in a figure are represented by the one beside the first plot. The color map usually ranges from 0 to 1 which corresponds to the probability from 0 to $100 \%$ of finding liquid at the selected location and time. For cases when the overall probability in the plot is low, a specific color map scales are used to enhance the resolution and are shown beside individual plot. Higher probability regions in the plot usually represent a more intact breakup structure which occurred at a more fixed position at certain time period over the repetitions.

Figures 8 and 9 show the averaged time-resolved 1D plots when the reading line is in the flow direction at various distances (denoted by the numbers below the plots) from the nozzle central axis. The results from a water jet, when the laser focus was $2.5 \mathrm{~mm}$ to the nozzle axis and the injection pressure was 1 bar, are shown in Fig. 8. For $d_{\mathrm{c}}=4 \mathrm{~mm}$ which is a quite short distance to the jet surface, a high probability stripe shaped region stretching diagonally across the figure can be observed. The stripe indicates the base of the bubble-induced breakup region that was moving along with the jet in the flow direction. The scratch shaped stripes, which are evenly distributed beside the main stripe, indicate the non-smooth surface of the turbulent jet that moves along the reading line. Bubble-induced breakup is easily distinguished because of the shape, the continuity and obviously higher probability of the main stripe. As the time increases, the main stripe becomes more widely spread and the probability gradient at the edge becomes less sharp. This corresponds to the breakup shown in Fig. 5. The base region of the deformation was growing wider at an early stage and later, when the ligament separation process started, the deformation structure became less intact. In the other plots, as the reading line is located further away from the nozzle central axis, the probability of the main stripe is reduced, because the front region of the deformation was less intact 

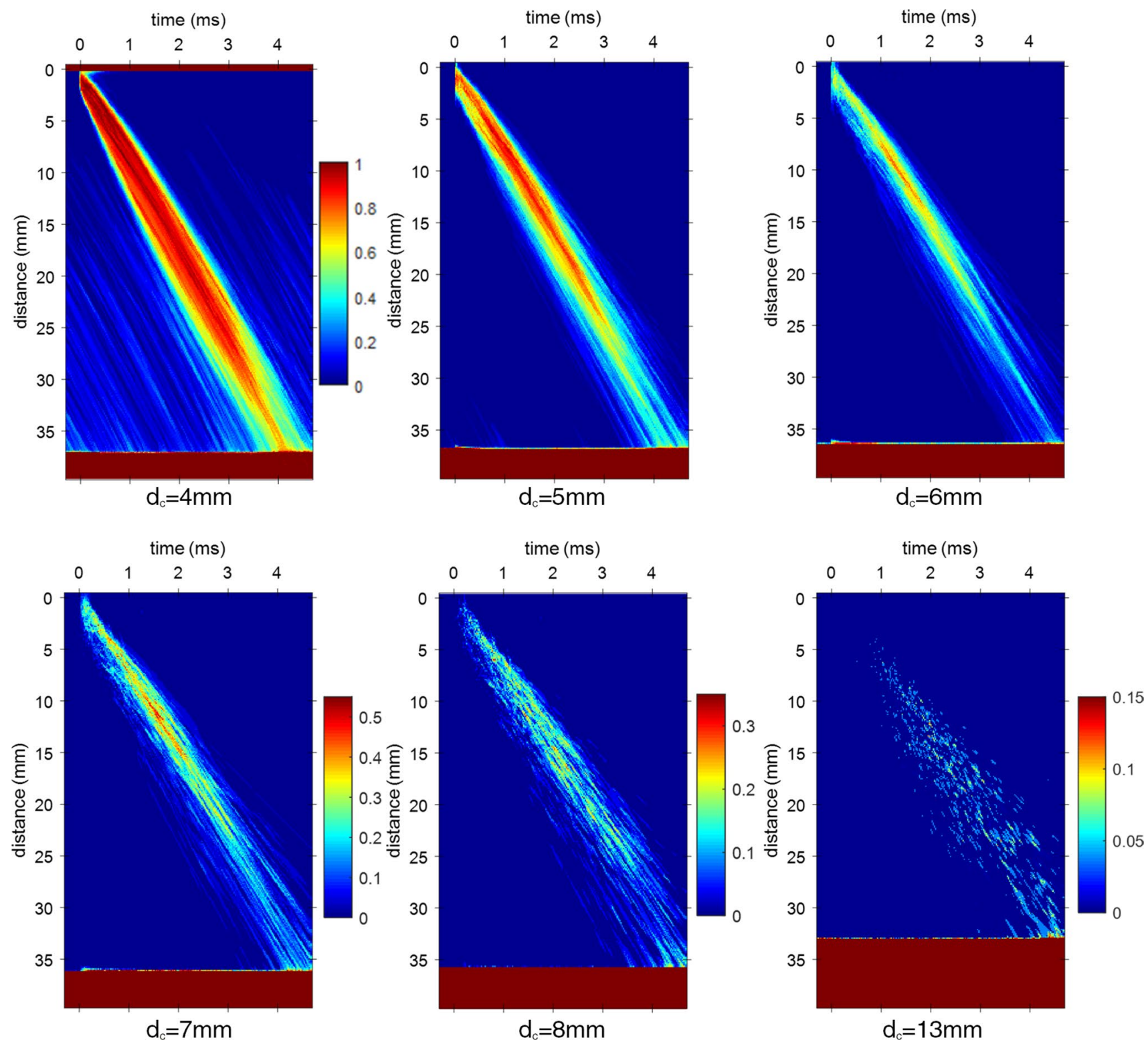

Fig. 8 Averaged time-resolved 1D (in the flow direction) plots of water jet breakup when the injection pressure was 1 bar and $d_{\mathrm{f}}=2.5 \mathrm{~mm}$. The number below each plot indicates the distance of the reading line from the nozzle axis. The results include 45 repetitions

and consisted of either liquid strings at the early stage or ligaments and droplets at later stage. No scratch shaped stripe can be found beside the main stripe when $d_{\mathrm{c}}$ is larger than $5 \mathrm{~mm}$, because there was no spontaneous breakup in this case. As illustrated in the previous section, the deformation structure was slowed down by shear. This phenomenon is reflected by the less steep slope of the main stripe at larger $d_{\mathrm{c}}$. The main stripe region is less continuous at larger $d_{\mathrm{c}}$ and its probability is much lower. The scattered stripes and dots within the region represent the ligaments and droplets far from the jet. At $d_{\mathrm{c}}=13 \mathrm{~mm}$ practically all liquid detected is in the form of drops. The short-stripe character with a similar slope as the main stripe closer to the jet, of many drops are an indication that they pass the reading line horizontally, during a limited time, and during this time also have a vertical velocity component.

The experimental conditions of the case shown in Fig. 9 were identical to Fig. 8 except that the liquid was changed to DPG10. The plots are quite similar to those in Fig. 8. The main stripes are slightly narrower, and their probability is slightly lower. This indicates smaller and less intact deformations which cannot be easily identified from individual videos. Slight scratch shaped stripes still exist at larger $d_{\mathrm{c}}$, i.e. $d_{\mathrm{c}}=6 \mathrm{~mm}$ and $7 \mathrm{~mm}$. These stripes represent the droplets spontaneously detaching from the jet and are different from the ones, which are related to the surface waves of the jet, in 

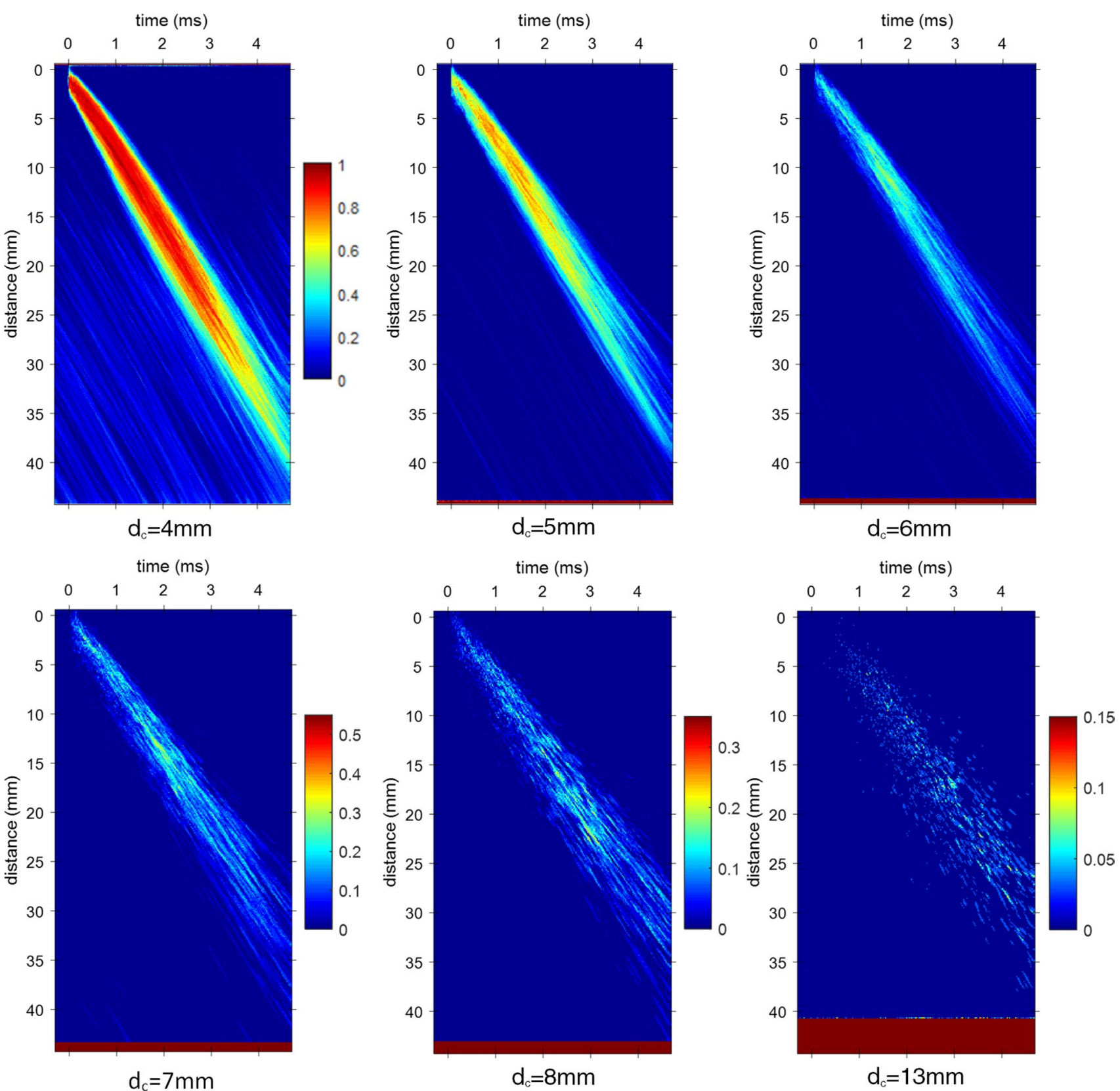

Fig. 9 Averaged time-resolved 1D (in the flow direction) plots of DPG10 jet breakup when the injection pressure was 1 bar and $d_{\mathrm{f}}=2.5 \mathrm{~mm}$. The number below each plot indicates the distance of the reading line from the nozzle axis. The results include 33 repetitions

the plots of $d_{\mathrm{c}}=4 \mathrm{~mm}$ and $5 \mathrm{~mm}$ in Fig. 8 . The lower surface tension of DPG10 resulted in spontaneous breakup of the jet at lower flow velocity.

Figures 10 and 11 show the averaged time-resolved 1D plots when the reading line is in the cross-flow direction at different distances (denoted by the number below each plot) from the nozzle orifice. The experimental conditions of the case shown here are identical to the ones in Fig. 8. On the left of each plot, there is a cylindrical region whose probability is 1 . This region indicates the main body of the jet. As $d_{\mathrm{o}}$ gets larger, the edge of the region becomes vaguer and wavier because the surface waves of jet are growing with increasing distance from the nozzle orifice. The protrusion on the right side of the cylindrical region indicates the bubble-induced surface deformation of the jet. It basically shows the profile of the deformation around the location $d_{\mathrm{o}}$ on the surface of jet. The protrusion becomes wider along the time axis when $d_{\mathrm{o}}$ is larger. This means that the deformation became wider when traveling in the flow direction. Along the horizontal axis, the main body of the protrusion 

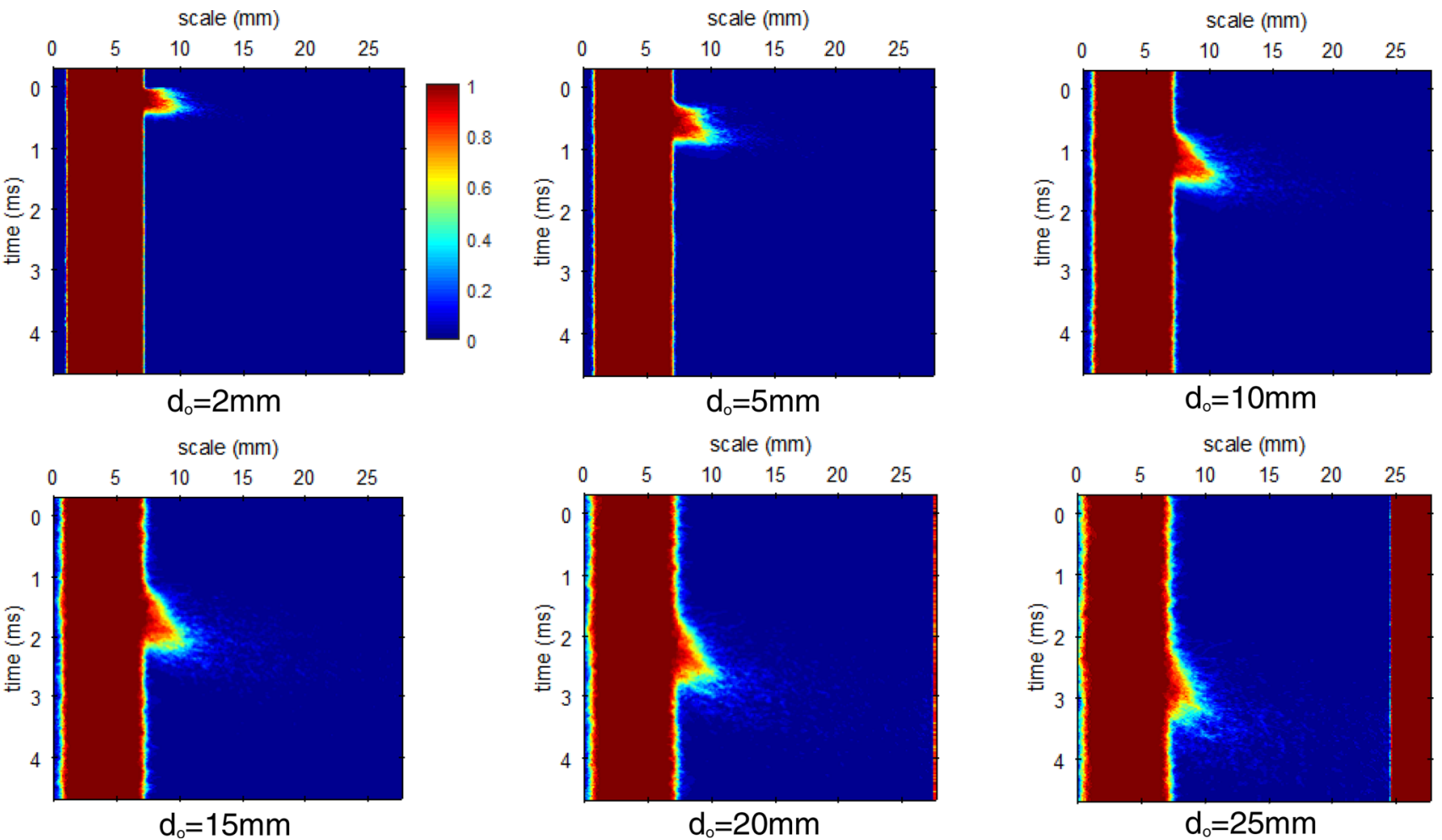

Fig. 10 Averaged time-resolved 1D (in the cross-flow direction) plots of water jet breakup when the injection pressure was 1 bar and $d_{\mathrm{f}}=2.5 \mathrm{~mm}$. The number below each plot indicates the distance of the reading line from the orifice. The results include 45 repetitions
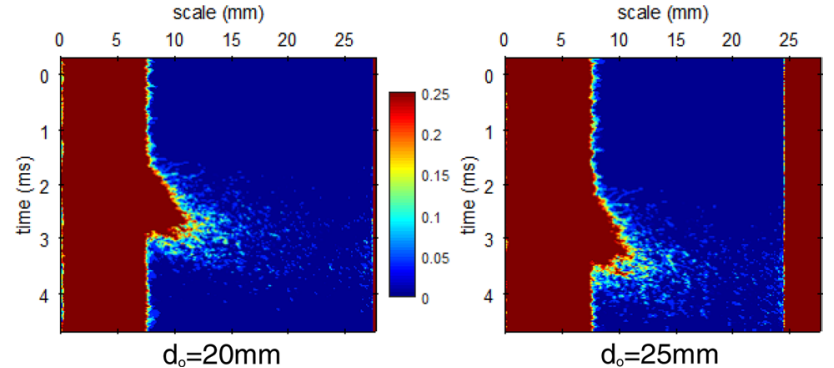

Fig. 11 Color map rescaled averaged time-resolved 1D (in the crossflow direction) plots of water jet breakup when the injection pressure was 1 bar and $d_{\mathrm{f}}=2.5 \mathrm{~mm}$. The number below each plot indicates the distance of the reading line from the orifice

with high liquid probability does not extend too much, but the distribution becomes more spread out with large amount of low probability dots, more easily seen when the color map scale was rescaled as in the plots of Fig. 11, which indicate the droplet detachments. The protrusions in the plots of $d_{\mathrm{o}}=10 \mathrm{~mm}$ and $15 \mathrm{~mm}$ are roughly in the shape of a triangle. This triangle corresponds to the one illustrated in Fig. 5. The triangle here is in the flipped direction because as time increasing, the bottom of the triangle region in Fig. 5 travels first to the reading line and becomes the top part of the triangle in the plot here. For $d_{\mathrm{o}}=20 \mathrm{~mm}$ and $25 \mathrm{~mm}$, the edge of the protrusion becomes vaguer because the breaking ligaments and detaching droplets made the deformation less intact, but the protrusion is still skewed to the direction of increasing time owning to shear. The close correlation between the averaged results here and the images in Fig. 5 indicates that although the turbulent jet surface introduced variation to bubble-induced jet breakup, regularity is still found when analyzing statistically.

The position of the laser focus in the jet has a significant impact on breakup (Zhou and Andersson 2018). Cases of different laser focus positions, i.e. distances from the nozzle central axis, are compared in the averaged time-resolved 1D plots shown in Fig. 12. The reading line is in the flow direction $\left(d_{\mathrm{c}}=5 \mathrm{~mm}\right)$ for Fig. 12a. When $d_{\mathrm{f}}=2.5 \mathrm{~mm}$, there is an obvious stripe region with high probability, which means the bubble-induced breakup was much more intense than those of other focus positions. For the plots of the other $d_{\mathrm{f}}$, the stripe regions are vaguer and with lower probabilities. The corresponding plots of Fig. 12b, where the reading line is in the cross-flow direction $\left(d_{\mathrm{o}}=10 \mathrm{~mm}\right)$, show the same trend as those of Fig. 12a. The protrusion in the plot of $d_{\mathrm{f}}=2.5 \mathrm{~mm}$ is larger than the ones in the other two plots. All the protrusions are slightly skewed to the direction of increasing time. The comparison of different cases here shows the same trend as the one illustrated in Figs. 4, 5, 6, 7 , although the injection pressure is different. 


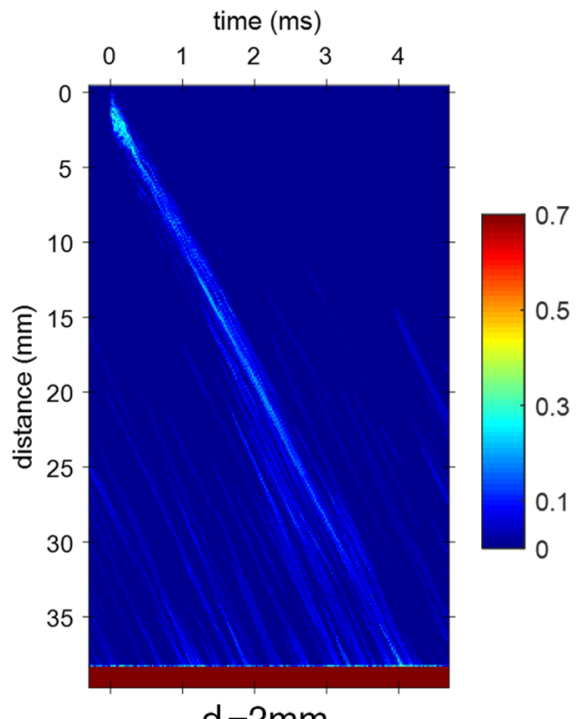

$\mathrm{d}_{1}=2 \mathrm{~mm}$

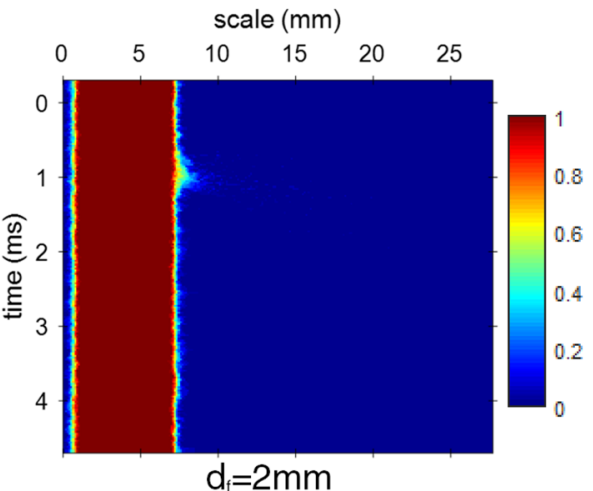

$\mathrm{d}_{\mathrm{f}}=2 \mathrm{~mm}$

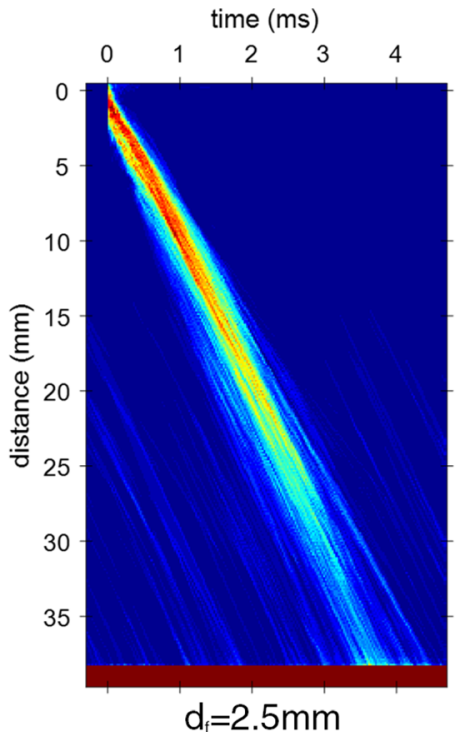

(a) $\mathrm{d}_{\mathrm{c}}=5 \mathrm{~mm}$

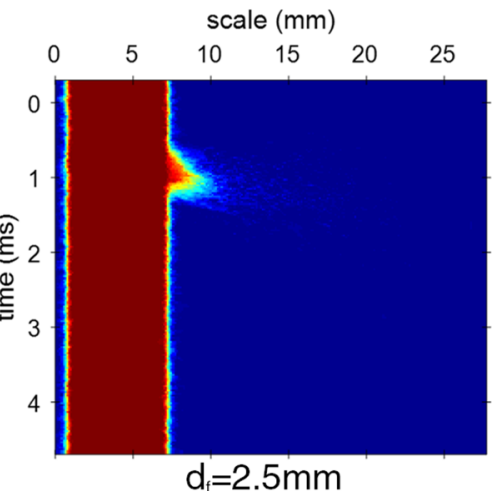

$\mathrm{d}_{\mathrm{f}}=2.5 \mathrm{~mm}$
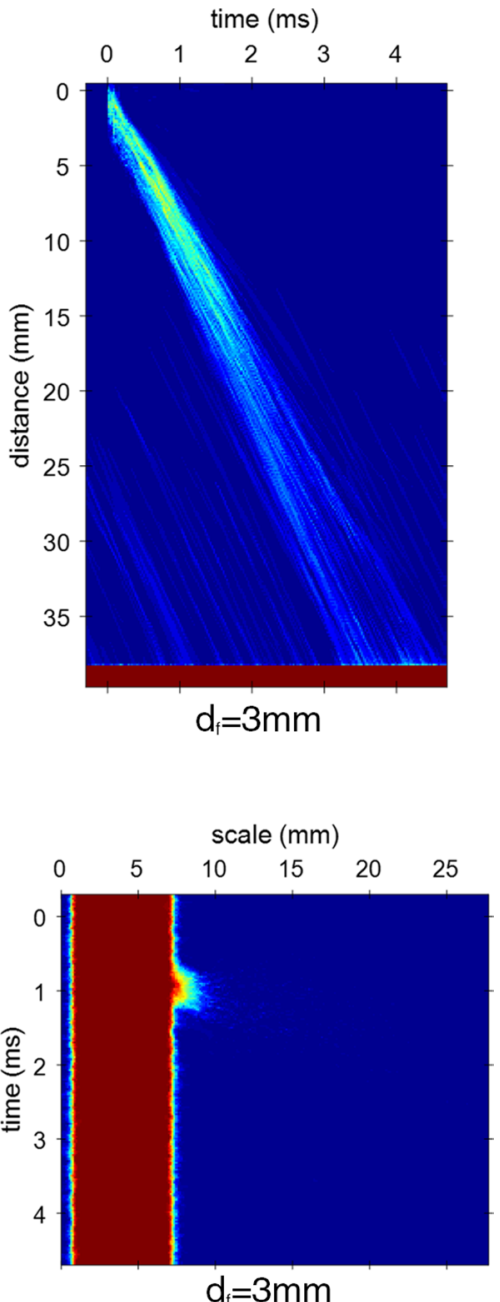

(b) $\mathrm{d}_{\mathrm{o}}=10 \mathrm{~mm}$

Fig. 12 Comparison of cases of different laser focus positions for water jet when the injection pressure was 1.5 bar and $\mathbf{a} d_{\mathrm{c}}=5 \mathrm{~mm}$, b $d_{\mathrm{o}}=10 \mathrm{~mm}$. The number below each plot indicates the distance of

Figure 13 shows plots to compare cases of different injection pressures and the laser focus is $2.5 \mathrm{~mm}$ from the nozzle central axis. In Fig. 13a, the reading line is in the flow direction $\left(d_{\mathrm{c}}=5 \mathrm{~mm}\right)$. As the injection pressure increases, the slope of the stripe becomes steeper due to the higher flow velocity. Furthermore, the main stripe region becomes narrower and the scratches beside the main stripe are more obvious and denser. These results correspond to the observations from Figs. 4, 5, 6, 7. Higher injection pressure resulted in smaller bubble-induced deformations while the turbulence on the jet surface and spontaneous breakup became more frequent. When the injection pressure is $5 \mathrm{bar}$, there are significant numbers of spontaneous breakup events from $15 \mathrm{~mm}$ downstream of the nozzle and it is hard to distinguish the main stripe from the scratches after $20 \mathrm{~mm}$ downstream. This means that the bubble-induced breakup only made a laser focus from the nozzle axis. The results include 31,36 and 35 repetitions for $d_{\mathrm{f}}=2 \mathrm{~mm}, 2.5 \mathrm{~mm}$ and $3 \mathrm{~mm}$, respectively

limited contribution compared to the spontaneous breakups at the downstream part of the jet. In Fig. 13b, the reading line is in the cross-flow direction $\left(d_{0}=5 \mathrm{~mm}\right)$. The protrusions in the plots of 3 bar and 5 bar are very narrow, because the bubble-induced deformations at higher injection pressure were much less intact and hard to be depicted in such plot with clear profile like the one at 1 bar. The cylindrical region, which represents the main body of the jet, on the left side of the plots becomes slightly wider as the injection pressure increases, because higher injection pressure results in more surface turbulence.

\subsection{Drop size distributions}

Image processing and droplet detection were performed by implementing the methods developed by Blaisot and 

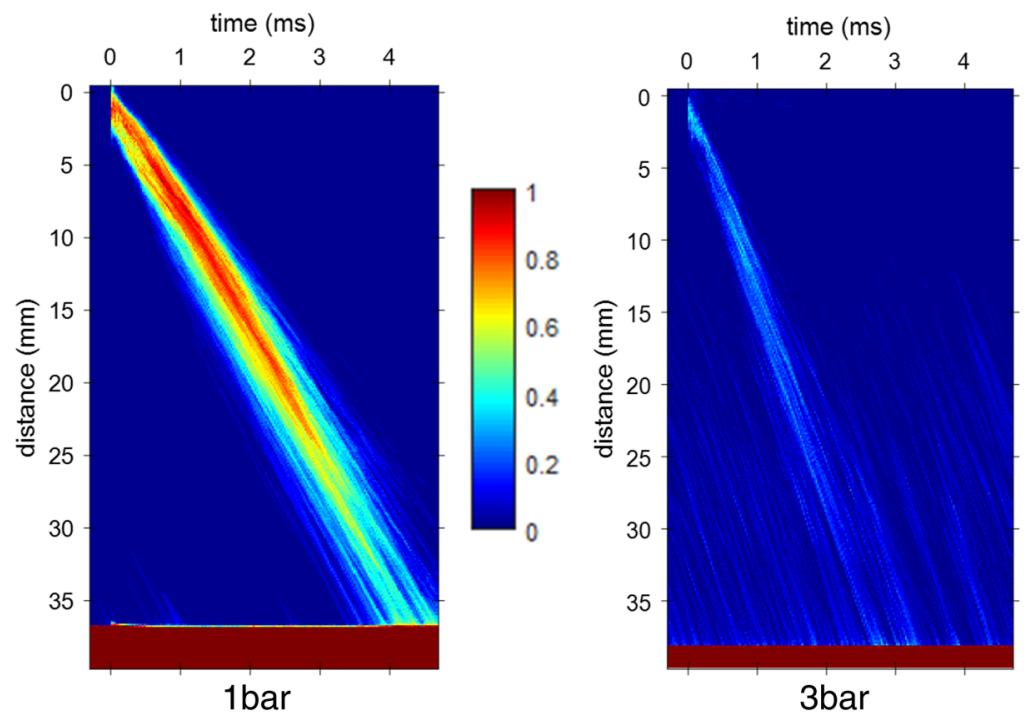

(a) $\mathrm{d}_{\mathrm{c}}=5 \mathrm{~mm}$

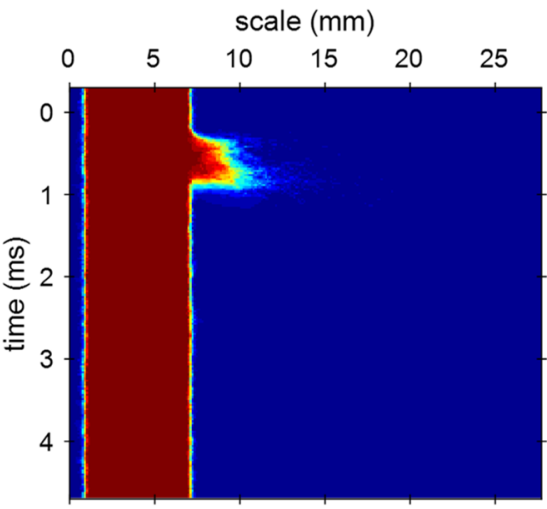

1 bar

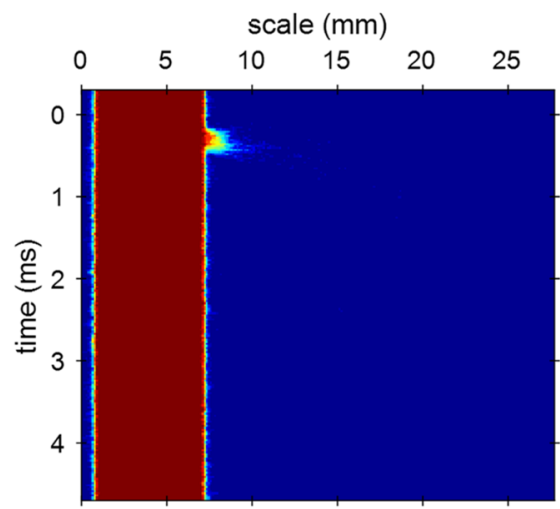

3 bar

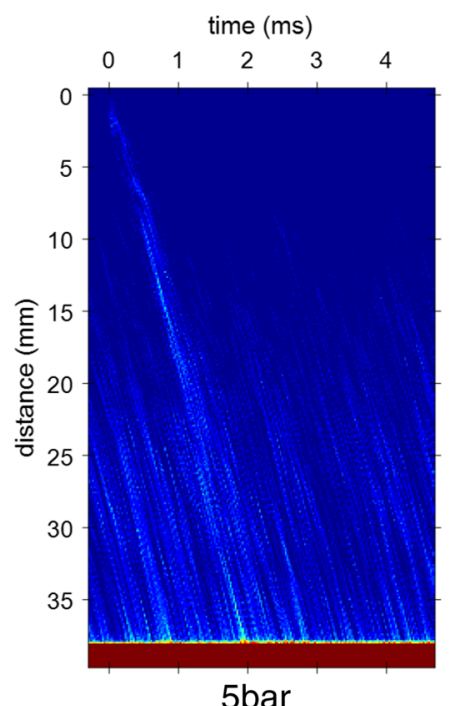

5 bar

(b) $\mathrm{d}_{\circ}=5 \mathrm{~mm}$

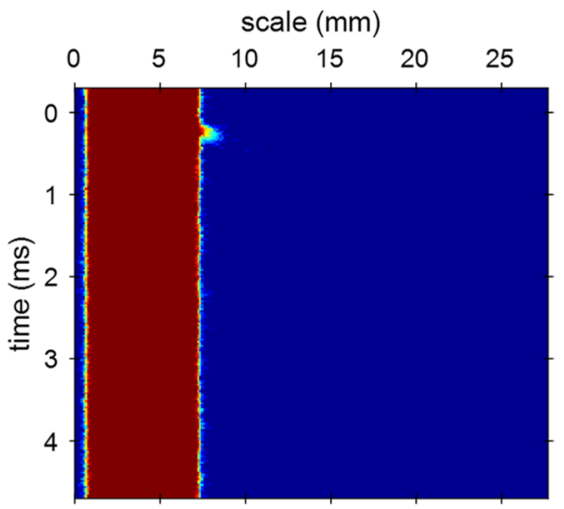

5 bar

Fig. 13 Comparison of cases of different injection pressures for water jet when the laser focus was 2.5 mm from the nozzle central axis and a $d_{\mathrm{c}}=5 \mathrm{~mm}, \mathbf{b} d_{\mathrm{o}}=5 \mathrm{~mm}$. The results include 45, 28 and 18 repetitions for $1 \mathrm{bar}, 3$ bar and 5 bar, respectively

Yon (2005), and Fdida and Blaisot (2009). The procedure included illumination normalization, which normalized the non-uniform background of the image, droplet detection, which localized individual droplets, and binarization to the local images which contained individual drops. Depth-of-field dependence of the objects in the image was solved by calibration of point spread function. Because the images obtained in this study had limited resolution, only the larger droplets (above $0.15 \mathrm{~mm}$ ) produced during the later stage of the bubble-induced breakup were analyzed, and the timing at which the larger ligaments had broken up into droplets was chosen. The sizes of the drops produced under different experimental conditions were fit to Rosin-Rammler distribution (Rosin 1933). One example is shown in Fig. 14. As shown in the plot, the Rosin-Rammler distribution can represent the drop size well with coefficient of determination 0.989 . The coefficient of determinations of different cases in the study varied from 0.933 to 0.994 .

There are parameters that determine a Rosin-Rammler distribution, i.e. the characteristic diameter, which is defined as the size at which $63.2 \%$ of the particles are smaller, and uniformity constant which indicates the uniformity of the size distribution (Mugele and Evans 1951). The higher the value of uniformity, the narrower the size distribution is. The value lies between 1.5 and 4 for most sprays but can be as high as 7 for some atomizers (Lefebvre and McDonell 2017). The characteristic diameters and uniformity constants of different cases are plotted in Figs. 15 and 16 respectively. The $X$-axes of the plots indicate the distance between the laser focus and the nozzle axis. As described above, for the cases of relatively higher injection pressure, droplets were also produced by spontaneous breakup beside the bubbleinduced breakup. For these cases, the droplets produced by 


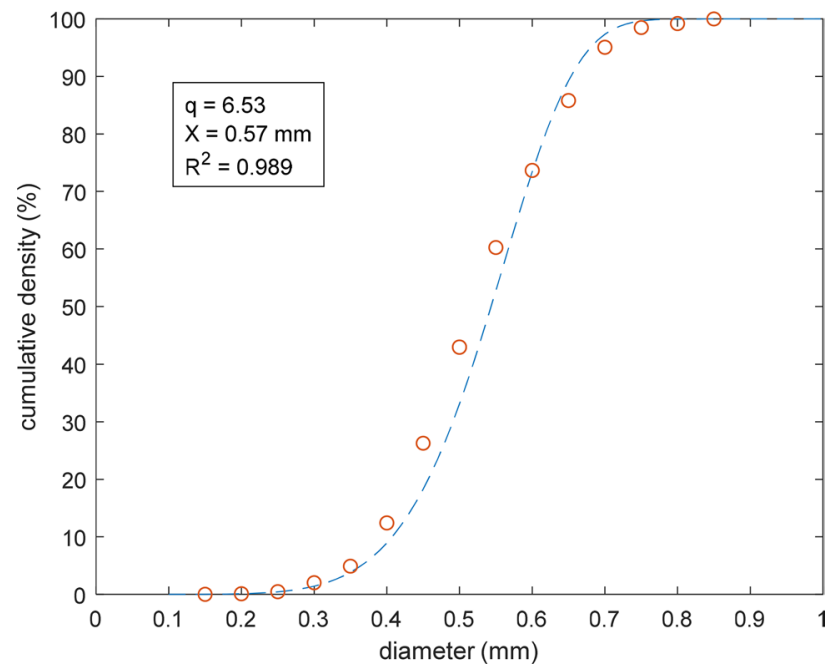

Fig. 14 Rosin-Rammler distribution fits to the drop size of bubbleinduced breakup of a water jet when the injection pressure was 1 bar, the distance of laser focus to the axis was $2 \mathrm{~mm}$. The uniformity constant, characteristic diameter and coefficient of determination are denoted by $q, X$ and $R^{2}$, respectively

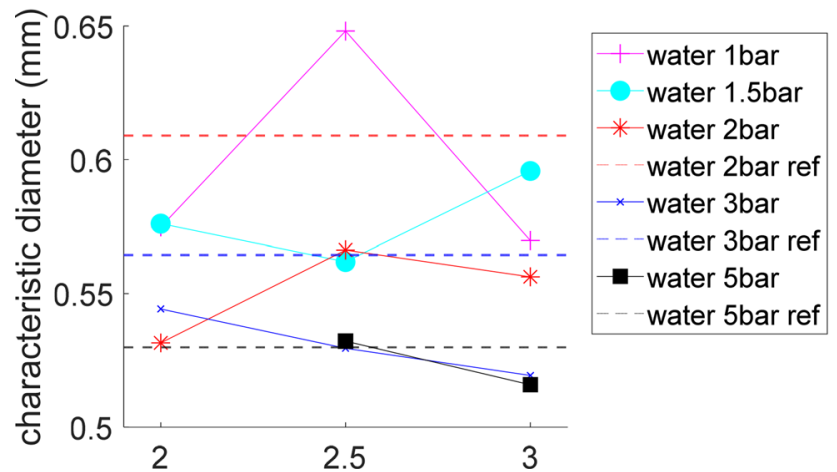

both mechanisms were mixed together in the images. So, it is necessary to analyze the drop sizes of spontaneous breakups separately as reference. The reference cases (indicated by the horizontal dashed lines) show the drop distributions in the absence of bubble-induced breakup.

The characteristic diameters are all in a relatively narrow range of $0.50-0.65 \mathrm{~mm}$, but several trends can be identified in Fig. 15. A higher jet velocity results in smaller diameter in general. The drop sizes of DPG10 are usually smaller than pure water. For lower injection pressures, i.e. 2 bar for water, 1.5 and 2 bar for DPG10, the drop sizes with bubble-induced breakup are clearly smaller than the reference cases. For higher injection pressures, the trend is not so clear. There are probably two reasons for the lack of clarity. One is that the size of the drops produced by the bubble-induced breakup was quite close to that from the spontaneous breakup under higher injection pressure. The other reason was discussed above in connection with Figs. 6 and 7. The smaller scale of the breakups at higher injection pressures made the drops produced by bubble-induced breakup less dominant compared to the ones from spontaneous breakup. The drop sizes for the lowest injection pressure cases, i.e. 1 bar for water and DPG10, follow a similar pattern. The drop sizes of both cases are clearly larger when the distance of laser focus to

Fig. 15 Characteristic diameters of the representative Rosin-Rammler distribution of the drops produced under different experimental conditions
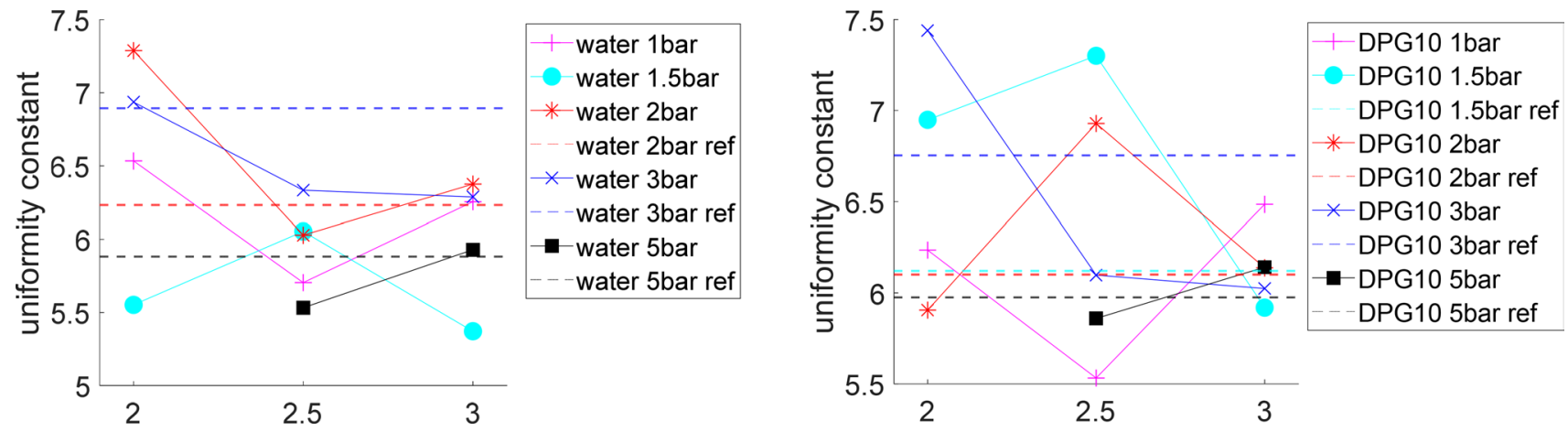

Fig. 16 Uniformities of the representative Rosin-Rammler distribution of the drops produced under different experimental conditions 
nozzle axis is $2.5 \mathrm{~mm}$. This indicates that in this condition the larger breakup structure with larger ligaments also broke up into larger droplets.

The uniformities under different conditions vary from 5.4 to 7.4 as shown in Fig. 16. Except for the cases of 2 bar, the uniformities for water and DPG10 follow a similar pattern with varying focus distance when comparing cases under the same injection pressure. This indicates that the position of the laser focus affected the uniformity of the drop size distribution.

\section{Conclusion}

The contribution of cavitation bubbles to the breakup of a turbulent liquid jet was investigated at flow conditions ranging from merely surface waves but no spontaneous breakup, to higher velocities where the spontaneous breakup and the bubble-induced ones were of similar intensity. The bubbles were artificially introduced by focusing laser light into the jet just below the nozzle at various distances from the central jet axis. Water and dipropylene glycol-water blend were used as the working liquids, and flow conditions at the exit of nozzle were adjusted by changing the injection pressure from $1 \mathrm{bar}$ to 5 bar. The deformation of the jet surface was imaged by a high-speed video camera. The evolution of surface deformation could be divided into two stages. During the first stage, liquid strings were growing and breaking into tiny droplets which made the front of the deformation appeared foggy. The strings were followed by a larger deformed structure which was growing as a relatively intact structure. The second stage covered the breakup of the larger structure. During this stage, the larger structure broke into ligaments and larger droplets. The averaged time-resolved 1D plot, which presents the probability to find liquid fragments at a certain position as a function of time after the laser pulse, was used to analyze the images. Bubble-induced breakup could easily be distinguished from the spontaneous breakup with this method. Drop sizes were analyzed by processing images and fitting the results to a Rosin-Rammler distribution. Some key findings are summarized as follows:

The radial position of the laser focus in the jet ejected from a 6-mm-diameter nozzle was found to affect the scale of the deformations, but the qualitative behavior was similar. Breakup was very intense when the laser focus was located at $2.5 \mathrm{~mm}$ to the nozzle central axis, compared to a deeper or shallower focus. The position of the laser focus affected the drop size in the case of 1 bar and the uniformity of the drop distribution in almost all cases, and the larger breakup at the focus position of $2.5 \mathrm{~mm}$ also resulted in larger drops.

At low injection pressure conditions, the structure of the bubble-induced breakup was much larger than the spontaneous one. When the injection pressure increased, i.e. the
Weber number was roughly larger than $3.6 \times 10^{5}$, the difference between these two breakup mechanisms was smaller, especially further downstream in the jets. This was a result of both a weaker bubble-induced breakup and more frequent spontaneous breakups. Higher injection pressure resulted in smaller sized droplets in general, and for drops formed from both bubble-induced and spontaneous breakups. When the injection pressure was lower than 3 bar, bubble-induced breakup produced smaller drops than spontaneous breakup. For higher injection pressure cases, i.e., the Weber number was roughly larger than $2 \times 10^{5}$, no evidence was found to support this trend.

The breakup structure of DPG10 jet was less intact, and more spontaneous breakup was found due to lower surface tension of the liquid.

The breakup process was highly affected by aerodynamic forces. The triangle pattern shown in the averaged time-resolved 1D plot confirmed the shear deformation statistically.

Funding Open access funding provided by Chalmers University of Technology.

Acknowledgements Financial support was obtained through the project "HAoS-Holistic Approach of Spray Injection through a Generalized Multi-Phase Framework", a Marie-Skłodowska-Curie Innovative Training Network, project ID 675676-HAoS-H2020-MSCA-ITN-2015.

Availability of data and materials Available upon request to the authors.

Open Access This article is licensed under a Creative Commons Attribution 4.0 International License, which permits use, sharing, adaptation, distribution and reproduction in any medium or format, as long as you give appropriate credit to the original author(s) and the source, provide a link to the Creative Commons licence, and indicate if changes were made. The images or other third party material in this article are included in the article's Creative Commons licence, unless indicated otherwise in a credit line to the material. If material is not included in the article's Creative Commons licence and your intended use is not permitted by statutory regulation or exceeds the permitted use, you will need to obtain permission directly from the copyright holder. To view a copy of this licence, visit http://creativecommons.org/licenses/by/4.0/.

\section{References}

Adrian FJ, Bohandy J, Kim BF, Jette AN, Thompson P (1987) A study of the mechanism of metal deposition by the laser-induced forward transfer process. J Vacuum Sci Technol B Microelectron Process Phenomena 5:1490-1494. https://doi.org/10.1116/1.583661

Alghamdi T, Thoroddsen ST, Hernández-Sánchez JF (2019) Ultrahigh speed visualization of a flash-boiling jet in a low-pressure environment. Int J Multiphase Flow 110:238-255. https://doi. org/10.1016/j.ijmultiphaseflow.2018.08.004

Baumgarten C, Stegemann J, Merker G (2002) A new model for cavitation induced primary break-up of diesel sprays. In: 18th Annual conference on liquid atomization \& spray systems, Zaragoza, Spain. ILASS-Europe 
Bempedelis N, Zhou J, Andersson M, Ventikos Y (2020) A numerical and experimental investigation into the early- and late-time dynamics of a bubble-free-surface system (submitted for publication)

Blaisot J, Yon J (2005) Droplet size and morphology characterization for dense sprays by image processing: application to the Diesel spray. Exp Fluids 39:977-994

Blake JR, Gibson DC (1981) Growth and collapse of a vapour cavity near a free surface. J Fluid Mech 111:123-140. https://doi. org/10.1017/S0022112081002322

Chahine GL (1977) Interaction between an oscillating bubble and a free surface. J Fluids Eng 99:709-716. https://doi.org/10.1115/1.34488 89

Dell'Aglio M, De Giacomo A, Kohsakowski S, Barcikowski S, Wagener P, Santagata A (2017) Pulsed laser ablation of wireshaped target in a thin water jet: effects of plasma features and bubble dynamics on the PLAL process. J Phys D Appl Phys 50:185204. https://doi.org/10.1088/1361-6463/aa652a

Duocastella M, Patrascioiu A, Fernández-Pradas JM, Morenza JL, Serra P (2010) Film-free laser forward printing of transparent and weakly absorbing liquids. Opt Express 18:21815-21825. https://doi.org/10.1364/OE.18.021815

Fdida N, Blaisot J-B (2009) Drop size distribution measured by imaging: determination of the measurement volume by the calibration of the point spread function. Meas Sci Technol 21:025501

Gadgil HP, Raghunandan B (2011) Some features of spray breakup in effervescent atomizers. Exp Fluids 50:329-338

He L, Ruiz F (1995) Effect of cavitation on flow and turbulence in plain orifices for high-speed atomization. Atomiz Sprays 5:569-584. https://doi.org/10.1615/AtomizSpr.v5.i6.30

Ji C, Li B, Zou J, Yang H (2017) Interaction of two spark generated bubbles beneath free surface. Exp Therm Fluid Sci 81:76-83. https://doi.org/10.1016/j.expthermflusci.2016.10.007

Kang YJ, Cho Y (2019) Gravity-capillary jet-like surface waves generated by an underwater bubble. J Fluid Mech 866:841-864. https ://doi.org/10.1017/jfm.2019.135

Keller JB, Kolodner II (1956) Damping of underwater explosion bubble oscillations. J Appl Phys 27:1152-1161. https://doi. org/10.1063/1.1722221

Kestin J, Sokolov M, Wakeham WA (1978) Viscosity of liquid water in the range $-8^{\circ} \mathrm{C}$ to $150{ }^{\circ} \mathrm{C}$. J Phys Chem Ref Data 7:941-948. https://doi.org/10.1063/1.555581

Kirk H et al (2001) Target studies with BNL E951 at the AGS. In: PACS2001. Proceedings of the 2001 particle accelerator conference (Cat. No. 01CH37268), 18-22 June 2001, vol 1532, pp 1535-1537. https://doi.org/10.1109/pac.2001.986739

Koukouvinis P, Gavaises M, Supponen O, Farhat M (2016) Simulation of bubble expansion and collapse in the vicinity of a free surface. Phys Fluids 28:052103. https://doi.org/10.1063/1.4949354

Kumar A, Sahu S (2020) Influence of nozzle geometry on primary and large-scale instabilities in coaxial injectors. Chem Eng Sci 221:115694. https://doi.org/10.1016/j.ces.2020.115694

Kyriazis N, Koukouvinis P, Gavaises M (2019) Numerical investigations on bubble-induced jetting and shock wave focusing: application on a needle-free injection. Proc R Soc A Math Phys Eng Sci 475:20180548. https://doi.org/10.1098/rspa.2018.0548

Lefebvre AH, McDonell VG (2017) Atomization and sprays. CRC, Boca Raton

Lin SP, Reitz RD (1998) Drop and spray formation from a liquid jet. Annu Rev Fluid Mech 30:85-105. https://doi.org/10.1146/annur ev.fluid.30.1.85

Mitroglou N, McLorn M, Gavaises M, Soteriou C, Winterbourne M (2014) Instantaneous and ensemble average cavitation structures in Diesel micro-channel flow orifices. Fuel 116:736-742. https:// doi.org/10.1016/j.fuel.2013.08.060
Mittal R, Ni R, Seo J-H (2020) The flow physics of COVID-19. J Fluid Mech 894:F2. https://doi.org/10.1017/jfm.2020.330

Mugele R, Evans H (1951) Droplet size distribution in sprays. Ind Eng Chem 43:1317-1324

Nurick WH (1976) Orifice cavitation and its effect on spray mixing. J Fluids Eng 98:681-687. https://doi.org/10.1115/1.3448452

Obreschkow D, Kobel P, Dorsaz N, de Bosset A, Nicollier C, Farhat M (2006) Cavitation bubble dynamics inside liquid drops in microgravity. Phys Rev Lett 97:094502. https://doi.org/10.1103/PhysR evLett.97.094502

Örley F, Trummler T, Hickel S, Mihatsch MS, Schmidt SJ, Adams NA (2015) Large-eddy simulation of cavitating nozzle flow and primary jet break-up. Phys Fluids 27:086101. https://doi. org/10.1063/1.4928701

Otsu N (1979) A threshold selection method from gray-level histograms. IEEE Trans Syst Man Cybern 9:62-66

Patrascioiu A, Fernández-Pradas JM, Morenza JL, Serra P (2014a) Film-free laser printing: jetting dynamics analyzed through time-resolved imaging. Appl Surf Sci 302:303-308. https://doi. org/10.1016/j.apsusc.2013.09.119

Patrascioiu A, Fernández-Pradas JM, Palla-Papavlu A, Morenza JL, Serra P (2014b) Laser-generated liquid microjets: correlation between bubble dynamics and liquid ejection. Microfluid Nanofluid 16:55-63. https://doi.org/10.1007/s10404-013-1218-5

Petrov NV, Schmidt AA (2015) Multiphase phenomena in underwater explosion. Exp Therm Fluid Sci 60:367-373. https://doi. org/10.1016/j.expthermflusci.2014.05.008

Purwar H, Lounnaci K, Idlahcen S, Rozé C, Blaisot J-B, Méès L, Michard M (2015) Effect of cavitation on velocity in the near-field of a diesel nozzle. In: 13th International conference on liquid atomization and spray systems, Tainan, Taiwan, 2015-08-23

Reitz RD (1978) Atomization and other breakup regimes of a liquid jet. $\mathrm{PhD}$ thesis, Princeton University

Reitz RD (1986) Mechanism of breakup of round liquid jets. Encyclopedia of fluid mechanics. Gulf Publishing Company, Houston

Robert E, Lettry J, Farhat M, Monkewitz PA, Avellan F (2007) Cavitation bubble behavior inside a liquid jet. Phys Fluids 19:067106. https://doi.org/10.1063/1.2744402

Robinson PB, Blake JR, Kodama T, Shima A, Tomita Y (2001) Interaction of cavitation bubbles with a free surface. J Appl Phys 89:8225-8237. https://doi.org/10.1063/1.1368163

Rosin P (1933) Laws governing the fineness of powdered coal. J Inst Fuel 7:29-36

Sallam KA, Dai Z, Faeth GM (2002) Liquid breakup at the surface of turbulent round liquid jets in still gases. Int J Multiphase Flow 28:427-449. https://doi.org/10.1016/S0301-9322(01)00067-2

Sedarsky D, Falgout Z, Rahm M, Linne M (2015) Characteristic data for primary breakup and spray formation. In: 27th Annual conference on liquid atomization and spray systems, Raleigh, North Carolina, 2015. ILASS-Americas

Singh G, Kourmatzis A, Gutteridge A, Masri AR (2020) Instability growth and fragment formation in air assisted atomization. J Fluid Mech 892:A29. https://doi.org/10.1017/jfm.2020.179

Sinibaldi G, Occhicone A, Pereira FA, Caprini D, Marino L, Michelotti F, Casciola CM (2019) Laser induced cavitation: plasma generation and breakdown shockwave. Phys Fluids 31:103302. https:// doi.org/10.1063/1.5119794

Soteriou C, Andrews R, Smith M (1995) Direct injection diesel sprays and the effect of cavitation and hydraulic flip on atomization. SAE Trans 104:128-153

Sovani SD, Sojka PE, Lefebvre AH (2001) Effervescent atomization. Progress Energy Combust Sci 27:483-521. https://doi. org/10.1016/S0360-1285(00)00029-0

Sun T, Teja AS (2004) Density, viscosity and thermal conductivity of aqueous solutions of propylene glycol, dipropylene glycol, and 
tripropylene glycol between $290 \mathrm{~K}$ and $460 \mathrm{~K}$. J Chem Eng Data 49:1311-1317

Supponen O, Kobel P, Obreschkow D, Farhat M (2015) The inner world of a collapsing bubble. Phys Fluids 27:091113. https://doi. org/10.1063/1.4931098

Tadjfar M, Jaberi A (2019) Effects of aspect ratio on the flow development of rectangular liquid jets issued into stagnant air. Int $\mathbf{J}$ Multiphase Flow 115:144-157. https://doi.org/10.1016/j.ijmul tiphaseflow.2019.03.011

Tagawa Y et al (2012) Highly focused supersonic microjets. Phys Rev X 2:031002. https://doi.org/10.1103/PhysRevX.2.031002

Thoroddsen ST, Takehara K, Etoh TG, Ohl C-D (2009) Spray and microjets produced by focusing a laser pulse into a hemispherical drop. Phys Fluids 21:112101. https://doi.org/10.1063/1.3253394

Tian Y, Xue B, Song J, Lu Y, Zheng R (2016) Stabilization of laserinduced plasma in bulk water using large focusing angle. Appl Phys Lett 109:061104. https://doi.org/10.1063/1.4960711

Tian Y, Wang L, Xue B, Chen Q, Li Y (2019) Laser focusing geometry effects on laser-induced plasma and laser-induced breakdown spectroscopy in bulk water. J Anal Atom Spectrometry 34:118-126

Vogel A, Nahen K, Theisen D, Noack J (1996) Plasma formation in water by picosecond and nanosecond Nd:YAG laser pulses. I.
Optical breakdown at threshold and superthreshold irradiance. IEEE J Select Top Quant Electron 2:847-860

Wang F, Fang T (2015) Liquid jet breakup for non-circular orifices under low pressures International. J Multiphase Flow 72:248-262. https://doi.org/10.1016/j.ijmultiphaseflow.2015.02.015

Westlye FR, Battistoni M, Skeen SA, Manin J, Pickett LM, Ivarsson A (2016) Penetration and combustion characterization of cavitating and non-cavitating fuel injectors under diesel engine conditions. In: SAE 2016 World congress and exhibition, Detroit, United States, 12-14 April 2016. SAE International. https://doi. org/10.4271/2016-01-0860

Zhang S, Wang SP, Zhang AM (2016) Experimental study on the interaction between bubble and free surface using a high-voltage spark generator. Phys Fluids 28:032109. https://doi.org/10.1063/1.49443 49

Zhou J, Andersson M (2018) Break-up induced by the collapse of lasergenerated cavitation bubbles in a liquid jet. In: 14th Triennial International Conference on Liquid Atomization and Spray Systems, ICLASS, Chicago, IL, USA, July 22-26 2018

Publisher's Note Springer Nature remains neutral with regard to jurisdictional claims in published maps and institutional affiliations. 